\title{
The Effects of Water Recycling on Flotation at a North American Concentrator-Part 1
}

\author{
Antonio Di Feo1 ${ }^{*}$, Saviz Mortazavi1, Sean Langley1, Lucie Morin', Gauri Prabhakar ${ }^{1}$, \\ André Demers' ${ }^{1}$, Ian Bedard ${ }^{2}$, Konstantin Volchek ${ }^{1}$ \\ ${ }^{1}$ Natural Resources Canada, CanmetMINING, Ottawa, Canada \\ ${ }^{2}$ Natural Resources Canada, CanmetMINING, Sudbury, Canada \\ Email: ${ }^{*}$ tony.difeo@canada.ca
}

How to cite this paper: Di Feo, A., Mortazavi, S., Langley, S., Morin, L., Prabhakar, G., Demers, A., Bedard, I. and Volchek, K. (2020) The Effects of Water Recycling on Flotation at a North American Concentrator-Part 1. Journal of Minerals and Materials Characterization and Engineering, 8, 240-276.

https://doi.org/10.4236/jmmce.2020.84016

Received: June 2, 2020

Accepted: July 20, 2020

Published: July 23, 2020

Copyright $\odot 2020$ by author(s) and Scientific Research Publishing Inc. This work is licensed under the Creative Commons Attribution International License (CC BY 4.0).

http://creativecommons.org/licenses/by/4.0/

\begin{abstract}
Water chemistry and its impact on mineral processing operations are not well understood and often not adequately monitored. CanmetMINING, as part of its water management research program, has been involved in a project initiated to identify opportunities for improving water recovery, water treatment, and recycling in the mining and mineral processing operations. One of the main objectives of this work is to evaluate and assess water chemistry and identify factors that impact mineral recovery, concentrate grade, and metal extraction efficiencies in order to understand and mitigate negative impacts of water recycling and improve process efficiency. In collaboration with a North American concentrator, CanmetMINING has been involved in assessing the water chemistry in the mill and evaluating water recycling options for select process streams to reduce fresh water intake and maximize recycling. The overall goal of the project is to investigate options for water recycling (increase the thickener overflow recirculation from thickener overflow tank) without affecting nickel and copper metallurgy. The results of the sampling campaigns showed that the water chemistry of the streams was fairly consistent throughout the year with no significant seasonal variations. The laboratory tests illustrated that when higher quantities of thickener overflow from thickener overflow were used, the nickel + copper grade versus nickel recovery curves shifted towards lower values. These observations were observed for the plant water samples obtained in April, June and August 2019.
\end{abstract}

\section{Keywords}

Copper Recovery, Flotation, Multivariate Analysis of Variance (MANOVA), Nickel Recovery, Process Water, Thickener Overflow, Water Recovery, Water Recycling 


\section{Introduction}

Water is a critical component as both a transport and a reaction medium in mineral processing and hydrometallurgical operations. Mining companies primarily focus on the environmental impact aspect of water quality issues and not on process efficiency. The importance of water quality on minerals and metals recovery is grossly underestimated and not fully understood despite the fact that most of the water in mining operations is used in mineral processing plants and flotation circuits. Understanding the effects of variations of water chemistry and quality on the mineral processing circuits' operational efficiency is critical in guiding decisions with respect to the water make-up and recycling [1] [2].

The mining industry is being compelled to reduce fresh water consumption due to various reasons. Some of these reasons are environmental, lack of fresh water, and government regulations [3] [4]. These operations may recycle water from tailings dams, thickener overflow stream, dewatering, filter products, industrial effluents and treated sewage [2] [4] [5]. Water recirculation is advantageous because less fresh water is used, however, these streams may have a high level of impurities, which can affect flotation performance.

Mineral separation uses a large quantity of water, which represents $80 \%$ to $90 \%$ of the pulp in flotation [2]. Water in flotation circuits is used for transporting solids and is a critical part in the processing of minerals [4], therefore, understanding its effects on flotation is critical. However, mill personnel do not often have sufficient understanding of the effects of recycled water on flotation and do not have the time and resources to carry out a detailed investigation to take remediation actions. Unfortunately, there may be significant economic losses mill personnel may not be able to estimate.

Flotation performance depends on water quality. The use of seawater results in lower molybdenum recovery due to calcium and magnesium hydroxyl complexes [6]. Studies on the impact of sewage effluent and other waste streams with high organic concentrations have shown that dissolved and suspended organics lower flotation rates and cause frothing problems in different mineral processing operations such as copper-molybdenum flotation [7]. Therefore, before water streams are recirculated, a holistic approach has to be taken by mining companies. Firstly, all the water streams should be assayed for dissolved species such as calcium, thiosalts, sulphate, TDS, total organic carbon, total inorganic carbon, and microbial load. The sampling of the concentrator should be done over the course of at least one year to determine whether there are any seasonal trends. Secondly, a detailed flotation program is required at the laboratory scale. The results of this test work will provide mill personnel with the effects of all the streams on flotation. Once this information becomes available, various ratios of the streams can be tested on flotation performance. If the streams are highly concentrated with species (in solutions and precipitates), various water treatment technologies may have to be considered.

Water treatment technologies should also be considered in the overall assess- 
ment of water recirculation in concentrators. Technologies such as vacuum membrane distillation, reverse osmosis and electro-dialysis can be used to treat part or the whole stream to reduce negative impacts on flotation performance. A thorough testing program has to be performed to determine the proportion of the stream and which streams have to be treated to maximize paymetal recovery. Afterward a detailed economic analysis is recommended to justify the utilization of such technologies.

This paper consists of two sections. In the first section, the characterization of the process water, flotation feeds (the circuit has two parallel roughers-scavenger banks-side A and side B, which will be described later) and the thickener overflow, from thickener overflow tank, streams are discussed. The measurements such as $\mathrm{pH}$, temperature and ORP of the streams are reported. In the second section, the results of flotation testing using process water (treated water that can be released to environment), thickener overflow and a combination of the two streams are discussed. The probable causes of the effects, pyrrhotite and gangue recoveries, of using thickener overflow on flotation are discussed.

\section{Experimental}

\subsection{Plant Samples}

Figure 1 illustrates the simplified plant flowsheet with the sampling points. The flowsheet consists of two grinding lines (lines A and B) in parallel and two rougher flotation lines in parallel (side A and side $B$ ). It is beyond the scope of this paper to describe the flotation circuit in more detail. Twelve streams were sampled for about a year and laboratory flotation tests were done with process water and thickener overflow.

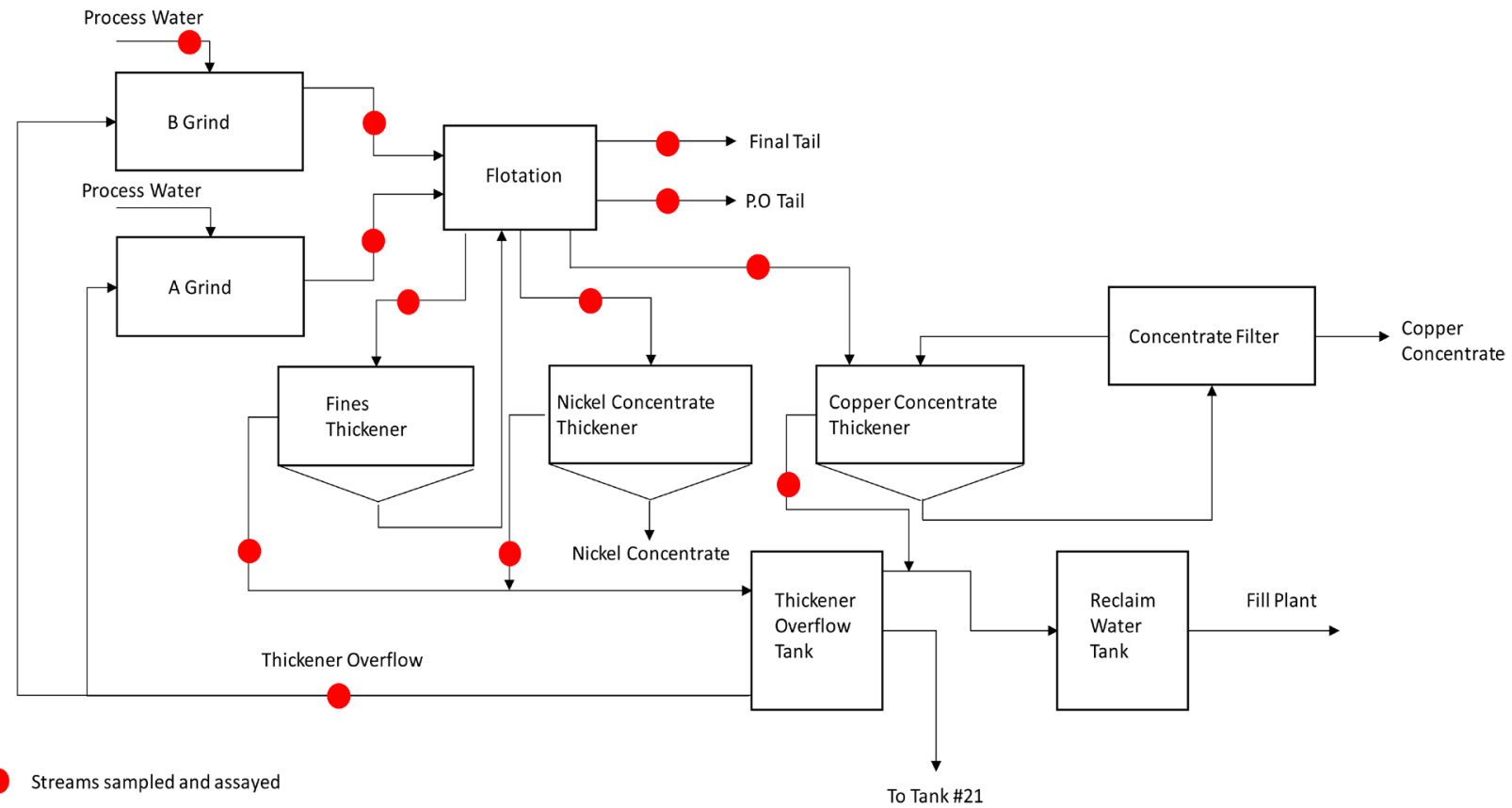

Figure 1. Flowsheet with sampling points. 
The steams shown in Figure 1, streams with red dots, were sampled for about a year. The following streams were sampled: process water, side A flotation feed, side B flotation feed, final tailings, Po tailings (pyrrhotite tailings), copper concentrate thickener feed, fines thickener feed, nickel concentrate thickener feed, thickener overflow, nickel concentrate thickener overflow, copper concentrate thickener overflow and fines thickener overflow. These streams were sampled on a monthly basis (except when the concentrator was shutdown). After the sampling was completed, the $\mathrm{pH}$, temperature and ORP were measured. Then two litres of each sample (pulp) were taken and immediately frozen for transport and subsequent microbial DNA extraction and analysis in the laboratory. The samples were then weighed and the solids were allowed to settle. Three $15 \mathrm{~mL}$ samples of each stream were frozen soon after sampling and sent to the laboratory for thiosalt assaying. The same was done for sulphate assaying. Three $100 \mathrm{~mL}$ aliquots of each stream were placed in a cooler after sampling and sent to the laboratory for total inorganic carbon (TIC), total organic carbon (TOC) and total carbon (TC) analysis. Three $15 \mathrm{~mL}$ and $50 \mathrm{~mL}$ samples of each stream were sent for inorganics (a few drops of nitric acid were added) and TDS analysis, respectively. The remainder of the samples was filtered, dried and the \% solids were determined.

Water samples for microbial analysis were decanted to separate the water and solids, then filtered through a Pall Supor 0.2 micron sterile filter unit. The filters were then processed using the Qiagen DNEasy Water extraction kit. Extracted DNA was quantified using a Qubit3 fluorometer with high sensitivity assay.

\subsection{Laboratory Testing}

The nickel-copper ore was crushed to $-2 \mathrm{~mm}$ ( -10 mesh), blended and split into $1 \mathrm{~kg}$ charges. Table 1 shows the external reference distribution for the ore used in this test work. All the relative standard distributions (RSD) were less than 5\%, which means that the sample was well blended.

The charges were ground to $56 \%$ passing 75 micrometres using a laboratory rod mill. The grinding media used was a combination of mild steel and stainless steel rods. The percent solids used in grinding was $60 \%$.

The laboratory rougher-scavenger flotation tests were done using a Denver flotation machine and a 1 litre cell. The reagents used were potassium isobutyl xanthate (PIBX) from Prospec Chemicals and Polyfroth W31 from Quadra Chemicals. The $\mathrm{pHs}$ for flotation were 9.2 and 8.0; these were adjusted using lime and sulphuric acid both from Fisher Scientific, respectively. Process water

Table 1.External reference distribution.

\begin{tabular}{ccccc}
\hline & Ni (\%) & Cu (\%) & Fe (\%) & Leco S (\%) \\
\hline Mean & 1.85 & 1.24 & 24.34 & 12.95 \\
St. Dev. & 0.05 & 0.02 & 0.45 & 0.25 \\
RSD (\%) & 2.74 & 1.65 & 1.83 & 1.93 \\
\hline
\end{tabular}


and thickener overflow obtained from the concentrator were used for the flotation tests (Table 2).

The process water and thickener overflow samples were received from the concentrator on a monthly basis (some months sampling was not done due to mill shutdown). Only the results of the flotation tests using the water types obtained in April 2019, June 2019 and August 2019 will be presented in this publication. All plant water samples were taken on the same day. Table 2 illustrates the process water and thickener overflow stream ratios used in the flotation test work (performed on a monthly basis with the exception for the months when the plant was not available). For the laboratory flotation tests, these ratios were randomized within the blocks (represented as Day 1, Day 2 and Day 3) to eliminate the effects of water aging, if any, between the series of tests. For each block or day, the three tests were completed on the same day.

\section{Statistical Analysis}

A multivariate analysis of variance (MANOVA) using blocking was performed to establish whether the nickel and copper recoveries were affected by the type of water used. Multivariate analysis of variance (MANOVA) is an extension of analysis of variance (ANOVA). MANOVA helps us to evaluate whether multiple levels of independent variables on their own or in combination with one another have effects on the response variables. Whereas, in ANOVA, differences among various group means on a single-response variable are studied, in MANOVA, the number of response variables can be increased to two or more. For this study, the MANOVA analysis results were obtained using SAS software. The family-wise error used was $5 \%$ for a family confidence of $95 \%$. The Bonferroni adjustment was used in the testing of significance of the effects. The Bonferroni correction was required to adjust the probability $(\alpha)$ values because of the increased risk of a type I error when making multiple statistical tests like we did in this case on the same sample of data. In the Bonferroni adjustment, which is made to reduce the likelihood of finding an erroneous significant effect (purely by random chance), the family-wise confidence level can be represented as 1 $\sum \alpha_{i}$ where $\alpha_{i}$ represents the confidence for every variable. For example, if $\alpha=$ 0.05 and two comparisons are considered in the statistical analysis, because of the Bonferroni adjustment, then we would do the significance testing with $0.05 / 2$ $=0.025(\alpha / \mathrm{m})$ where $\mathrm{m}$ is the number of comparisons. The $\alpha / \mathrm{m}(0.05 / \mathrm{m})$ ratio

Table 2. Water ratios used for flotation tests.

\begin{tabular}{llll}
\hline Test & Day 1 & Day 2 & Day 3 \\
\hline 1 & $100 \%$ process water & $\begin{array}{l}50 \% \text { process water } / 50 \% \\
\text { thickener overflow stream }\end{array}$ & $\begin{array}{l}50 \% \text { process water } / 50 \% \\
\text { thickener overflow stream }\end{array}$ \\
2 & $\begin{array}{l}50 \% \text { process water } / 50 \% \\
\text { thickener overflow stream }\end{array}$ & $100 \%$ process water & $\begin{array}{l}100 \% \text { thickener overflow } \\
\text { stream }\end{array}$ \\
3 & $100 \%$ thickener overflow stream & $100 \%$ thickener overflow stream & $100 \%$ process water \\
\hline
\end{tabular}


was compared to the probability $>F$ statistic ( $\operatorname{Pr}>F$ which is equivalent to $p$ ) in the SAS output. If $0.05 / \mathrm{m}$ was less than $\operatorname{Pr}>F$ (SAS output), then the factor in question was considered to be significant at the $95 \%$ level. The methodology is described in [8].

There are three major prerequisites for MANOVA to be applicable; the data have to be independent and normal and the variance has to be constant. These conditions were verified prior to performing the MANOVA analysis and were found to meet the requirements for all the tests discussed. The following are the null hypothesis tests used in the analysis of the test work results.

\subsection{Manova}

For the notation in this section, PW stands for process water and TK O/F stands for thickener overflow. Also, $\mu$ stands for the mean of the variable in question. For example, $\mu_{\mathrm{Ni} \text { rec }}$ signifies the mean of the nickel recovery.

Day (block):

Null hypothesis

$$
\left.\left(\begin{array}{l}
\mu_{\mathrm{Ni} \text { Rec }} \\
\mu_{\mathrm{Cu} \text { Rec }}
\end{array}\right) \text { Day } 1=\left(\begin{array}{l}
\mu_{\mathrm{Ni} \text { Rec }} \\
\mu_{\mathrm{Cu} \text { Rec }}
\end{array}\right) \text { Day 2=( } \begin{array}{l}
\mu_{\mathrm{Ni} \text { Rec }} \\
\mu_{\mathrm{Cu} \text { Rec }}
\end{array}\right) \text { Day } 3
$$

Alternate hypothesis

$$
\left(\begin{array}{l}
\mu_{\mathrm{Ni} \text { Rec }} \\
\mu_{\mathrm{Cu} \text { Rec }}
\end{array}\right) \text { Day } 1 \neq\left(\begin{array}{l}
\mu_{\mathrm{Ni} \text { Rec }} \\
\mu_{\mathrm{Cu} \text { Rec }}
\end{array}\right) \text { Day } 2 \neq\left(\begin{array}{l}
\mu_{\mathrm{Ni} \text { Rec }} \\
\mu_{\mathrm{Cu} \text { Rec }}
\end{array}\right) \text { Day } 3
$$

or

$$
\left(\begin{array}{l}
\mu_{\mathrm{Ni} \text { Rec }} \\
\mu_{\mathrm{Cu} \text { Rec }}
\end{array}\right) \text { Day } 1=\left(\begin{array}{l}
\mu_{\mathrm{Ni} \mathrm{Rec}} \\
\mu_{\mathrm{Cu} \text { Rec }}
\end{array}\right) \text { Day } 2 \neq\left(\begin{array}{l}
\mu_{\mathrm{Ni} \text { Rec }} \\
\mu_{\mathrm{Cu} \text { Rec }}
\end{array}\right) \text { Day } 3
$$

or

$$
\left(\begin{array}{l}
\mu_{\mathrm{Ni} \mathrm{Rec}} \\
\mu_{\mathrm{Cu} \text { Rec }}
\end{array}\right) \text { Day } 1 \neq\left(\begin{array}{l}
\mu_{\mathrm{Ni} \mathrm{Rec}} \\
\mu_{\mathrm{Cu} \text { Rec }}
\end{array}\right) \text { Day } 2=\left(\begin{array}{l}
\mu_{\mathrm{Ni} \mathrm{Rec}} \\
\mu_{\mathrm{Cu} \text { Rec }}
\end{array}\right) \text { Day } 3
$$

Water Ratio:

Null hypothesis

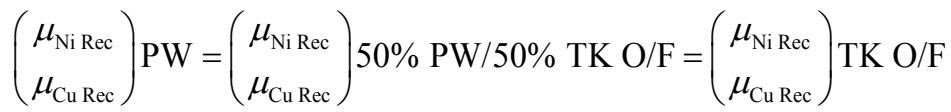

Alternate hypothesis

$$
\left(\begin{array}{l}
\mu_{\mathrm{Ni} \text { Rec }} \\
\mu_{\mathrm{Cu} \text { Rec }}
\end{array}\right) \mathrm{PW} \neq\left(\begin{array}{l}
\mu_{\mathrm{Ni} \mathrm{Rec}} \\
\mu_{\mathrm{Cu} \text { Rec }}
\end{array}\right) 50 \% \mathrm{PW} / 50 \% \mathrm{TK} \mathrm{O} / \mathrm{F} \neq\left(\begin{array}{l}
\mu_{\mathrm{Ni} \text { Rec }} \\
\mu_{\mathrm{Cu} \text { Rec }}
\end{array}\right) \mathrm{TK} \mathrm{O} / \mathrm{F}
$$

or

$$
\left(\begin{array}{l}
\mu_{\mathrm{Ni} \text { Rec }} \\
\mu_{\mathrm{Cu} \text { Rec }}
\end{array}\right) \mathrm{PW}=\left(\begin{array}{l}
\mu_{\mathrm{Ni} \text { Rec }} \\
\mu_{\mathrm{Cu} \text { Rec }}
\end{array}\right) 50 \% \text { PW/50\% TK O/F } \neq\left(\begin{array}{l}
\mu_{\mathrm{Ni} \mathrm{Rec}} \\
\mu_{\mathrm{Cu} \text { Rec }}
\end{array}\right) \text { TK O/F }
$$

or

$$
\left(\begin{array}{l}
\mu_{\mathrm{Ni} \text { Rec }} \\
\mu_{\mathrm{Cu} \text { Rec }}
\end{array}\right) \mathrm{PW} \neq\left(\begin{array}{l}
\mu_{\mathrm{Ni} \mathrm{Rec}} \\
\mu_{\mathrm{Cu} \text { Rec }}
\end{array}\right) 50 \% \mathrm{PW} / 50 \% \mathrm{TK} \mathrm{O} / \mathrm{F}=\left(\begin{array}{l}
\mu_{\mathrm{Ni} \text { Rec }} \\
\mu_{\mathrm{Cu} \text { Rec }}
\end{array}\right) \mathrm{TK} \mathrm{O} / \mathrm{F}
$$


Orthogonal Contrast tests

Differences among treatments can be done using orthogonal contrast. Contrasts involve linear combinations of the variables [8].

Process water versus $50 \%$ process water $/ 50 \%$ thickener overflow.

Null hypothesis

$$
\left(\begin{array}{l}
\mu_{\mathrm{Ni} \text { Rec }} \\
\mu_{\mathrm{Cu} \text { Rec }}
\end{array}\right) \mathrm{PW}=\left(\begin{array}{l}
\mu_{\mathrm{Ni} \mathrm{Rec}} \\
\mu_{\mathrm{Cu} \text { Rec }}
\end{array}\right) 50 \% \mathrm{PW} / 50 \% \mathrm{TK} \mathrm{O} / \mathrm{F}
$$

Alternate hypothesis

$$
\left(\begin{array}{l}
\mu_{\mathrm{Ni} \text { Rec }} \\
\mu_{\mathrm{Cu} \text { Rec }}
\end{array}\right) \mathrm{PW} \neq\left(\begin{array}{l}
\mu_{\mathrm{Ni} \operatorname{Rec}} \\
\mu_{\mathrm{Cu} \text { Rec }}
\end{array}\right) 50 \% \mathrm{PW} / 50 \% \text { TK O/F }
$$

Process water versus thickener overflow.

Null hypothesis

$$
\left(\begin{array}{l}
\mu_{\mathrm{Ni} \text { Rec }} \\
\mu_{\mathrm{Cu} \text { Rec }}
\end{array}\right) \mathrm{PW}=\left(\begin{array}{l}
\mu_{\mathrm{Ni} \text { Rec }} \\
\mu_{\mathrm{Cu} \text { Rec }}
\end{array}\right) \mathrm{TK} \mathrm{O/F}
$$

Alternate hypothesis

$$
\left(\begin{array}{l}
\mu_{\mathrm{Ni} \mathrm{Rec}} \\
\mu_{\mathrm{Cu} \text { Rec }}
\end{array}\right) \mathrm{PW} \neq\left(\begin{array}{l}
\mu_{\mathrm{Ni} \mathrm{Rec}} \\
\mu_{\mathrm{Cu} \text { Rec }}
\end{array}\right) \mathrm{TK} \mathrm{O} / \mathrm{F}
$$

Thickener overflow versus $50 \%$ process water $/ 50 \%$ thickener overflow. Null hypothesis

$$
\left(\begin{array}{l}
\mu_{\mathrm{Ni} \text { Rec }} \\
\mu_{\mathrm{Cu} \text { Rec }}
\end{array}\right) \mathrm{TK} \mathrm{O/F}=\left(\begin{array}{l}
\mu_{\mathrm{NiRec}} \\
\mu_{\mathrm{Cu} \text { Rec }}
\end{array}\right) 50 \% \mathrm{PW} / 50 \% \mathrm{TK} \mathrm{O} / \mathrm{F}
$$

Alternate hypothesis

$$
\left(\begin{array}{l}
\mu_{\mathrm{Ni} \text { Rec }} \\
\mu_{\mathrm{Cu} \text { Rec }}
\end{array}\right) \text { TK O/F } \neq\left(\begin{array}{l}
\mu_{\mathrm{Ni} \text { Rec }} \\
\mu_{\mathrm{Cu} \text { Rec }}
\end{array}\right) 50 \% \mathrm{PW} / 50 \% \mathrm{TK} \mathrm{O} / \mathrm{F} .
$$

\subsection{Anova}

Nickel recovery

Process water versus $50 \%$ process water $/ 50 \%$ thickener overflow.

Null hypothesis

$$
\left(\mu_{\mathrm{Ni} \text { Rec }}\right) \mathrm{PW}=\left(\mu_{\mathrm{Ni} \text { Rec }}\right) 50 \% \mathrm{PW} / 50 \% \mathrm{TK} \mathrm{O} / \mathrm{F}
$$

Alternate hypothesis

$$
\left(\mu_{\mathrm{Ni} \text { Rec }}\right) \mathrm{PW} \neq\left(\mu_{\mathrm{Ni} \text { Rec }}\right) 50 \% \mathrm{PW} / 50 \% \text { TK O/F }
$$

Process water versus thickener overflow.

Null hypothesis

$$
\left(\mu_{\mathrm{Ni} \text { Rec }}\right) \mathrm{PW}=\left(\mu_{\mathrm{Ni} \text { Rec }}\right) \mathrm{TK} \mathrm{O} / \mathrm{F}
$$

Alternate hypothesis

$$
\left(\mu_{\mathrm{Ni} \text { Rec }}\right) \mathrm{PW} \neq\left(\mu_{\mathrm{Ni} \text { Rec }}\right) \mathrm{TK} \mathrm{O} / \mathrm{F}
$$


Thickener overflow versus $50 \%$ process water $/ 50 \%$ thickener overflow. Null hypothesis

$$
\left(\mu_{\mathrm{Ni} \text { Rec }}\right) \mathrm{TK} \mathrm{O} / \mathrm{F}=\left(\mu_{\mathrm{NiRec}}\right) 50 \% \mathrm{PW} / 50 \% \mathrm{TK} \mathrm{O} / \mathrm{F}
$$

Alternate hypothesis

$$
\left(\mu_{\mathrm{Ni} \text { Rec }}\right) \mathrm{TK} \mathrm{O} / \mathrm{F} \neq\left(\mu_{\mathrm{NiRec}}\right) 50 \% \mathrm{PW} / 50 \% \mathrm{TK} \mathrm{O} / \mathrm{F}
$$

Copper recovery

Process water versus $50 \%$ process water $/ 50 \%$ thickener overflow.

Null hypothesis

$$
\left(\mu_{\mathrm{Cu} \text { Rec }}\right) \mathrm{PW}=\left(\mu_{\mathrm{Cu} \text { Rec }}\right) 50 \% \mathrm{PW} / 50 \% \text { TK O/F }
$$

Alternate hypothesis

$$
\left(\mu_{\mathrm{Cu} \text { Rec }}\right) \mathrm{PW} \neq\left(\mu_{\mathrm{Cu} \text { Rec }}\right) 50 \% \mathrm{PW} / 50 \% \text { TK O/F }
$$

Process water versus thickener overflow.

Null hypothesis

$$
\left(\mu_{\mathrm{Cu} \text { Rec }}\right) \mathrm{PW}=\left(\mu_{\mathrm{Cu} \text { Rec }}\right) \mathrm{TK} \mathrm{O} / \mathrm{F}
$$

Alternate hypothesis

$$
\left(\mu_{\mathrm{Cu} \text { Rec }}\right) \mathrm{PW} \neq\left(\mu_{\mathrm{Cu} \text { Rec }}\right) \mathrm{TK} \mathrm{O} / \mathrm{F}
$$

Thickener overflow versus $50 \%$ process water $/ 50 \%$ thickener overflow. Null hypothesis

$$
\left(\mu_{\text {Cu Rec }}\right) \text { TK O/F }=\left(\mu_{\text {Cu Rec }}\right) 50 \% \text { PW/50\% TK O/F }
$$

Alternate hypothesis

$$
\left(\mu_{\text {Cu Rec }}\right) \text { TK O/F } \neq\left(\mu_{\text {Cu Rec }}\right) 50 \% \text { PW/50\% TK O/F }
$$

\subsection{Confidence Intervals for Flotation Tests}

The method described by Napier-Munn (2012) [9] was used to establish the confidence intervals $(C D)$ for the flotation tests.

$$
C l= \pm \frac{s t_{\alpha}}{\sqrt{n}}
$$

where $t=2.92$ for $90 \%$ confidence, $s$ is the standard deviation and $n$ is the number of replicates ( $n=3$ for the flotation testing in this work). Note that a $90 \%$ confidence level was used to create error bars for the flotation test results.

\section{Results}

The results of the streams that can impact flotation will be discussed. These are the process water, side A flotation feed, side B flotation feed, and thickener overflow streams. The sampling period was from November 2017 to June 25, 2019. The process water comes from the tailings treatment system (this is clean water) and the thickener overflow is recirculated back to the grinding circuit. A portion of the thickener overflow is recirculated. 


\subsection{Stream Characterization}

Table 3 shows the sampling dates for the process water, A side flotation feed, B side flotation feed, and thickener overflow. Certain streams were not sampled during this period.

Table 3. Sampling dates for the concentrator streams (Figures 2-4, Figures 6-18).

\begin{tabular}{|c|c|c|c|c|}
\hline Date & Process Water & $\begin{array}{c}\text { A Side Flotation } \\
\text { Feed }\end{array}$ & $\begin{array}{c}\text { B Side Flotation } \\
\text { Feed }\end{array}$ & $\begin{array}{c}\text { Thickener } \\
\text { overflow Stream }\end{array}$ \\
\hline November 23, 2017 & Sampled & Not sampled & Sampled & Sampled \\
\hline January 4, 2018 & Sampled & Sampled & Not sampled & Sampled \\
\hline January 19, 2018 & Sampled & Sampled & Sampled & Sampled \\
\hline February 9, 2018 & Sampled & Sampled & Sampled & Sampled \\
\hline February 15, 2018 & Sampled & Sampled & Sampled & Sampled \\
\hline March 2, 2018 & Sampled & Sampled & Not sampled & Sampled \\
\hline March 22, 2018 & Sampled & Sampled & Sampled & Sampled \\
\hline June 12, 2018 & Sampled & Sampled & Sampled & Sampled \\
\hline June 26, 2018 & Sampled & Sampled & Sampled & Sampled \\
\hline July 31, 2018 & Sampled & Sampled & Not sampled & Sampled \\
\hline August 21, 2018 & Sampled & Sampled & Sampled & Sampled \\
\hline October 2, 2018 & Sampled & Sampled & Sampled & Sampled \\
\hline December 13, 2018 & Sampled & Sampled & Sampled & Sampled \\
\hline January 15, 2019 & Sampled & Sampled & Sampled & Sampled \\
\hline February 21, 2019 & Sampled & Sampled & Sampled & Sampled \\
\hline April 3, 2019 & Sampled & Sampled & Sampled & Sampled \\
\hline May 14, 2019 & Sampled & Sampled & Sampled & Sampled \\
\hline June 25, 2019 & Sampled & Sampled & Not sampled & Sampled \\
\hline
\end{tabular}

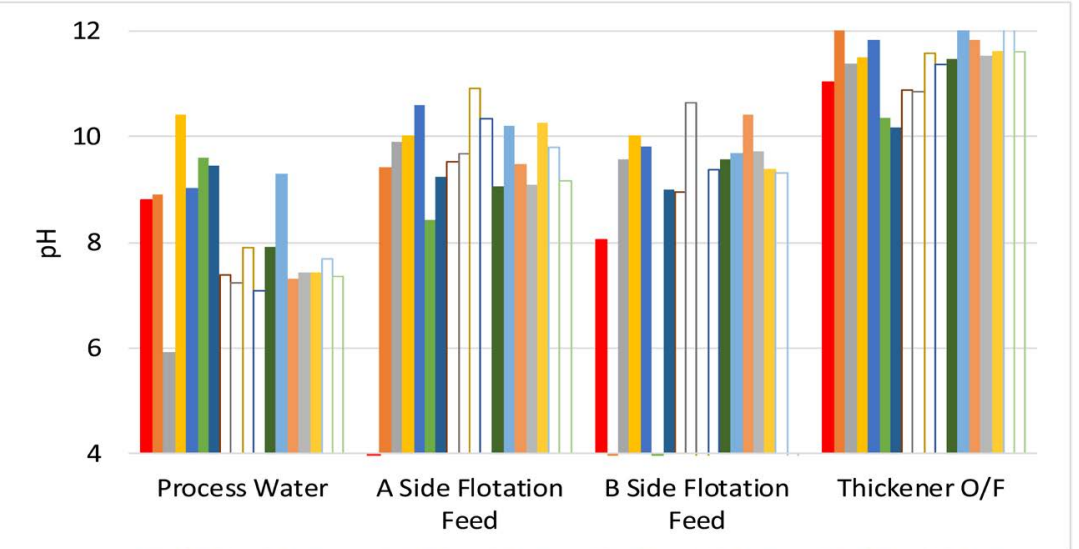

Figure 2. $\mathrm{pH}$ for process water, side A and side B flotation feeds and thickener overflow from November 2017 to June 2019. A side flotation was not sampled on November 23, 2017. B Side flotation feed was not sampled on January 4, 2018, March 2, 2018, July 31, 2018 and June 25, 2019. 


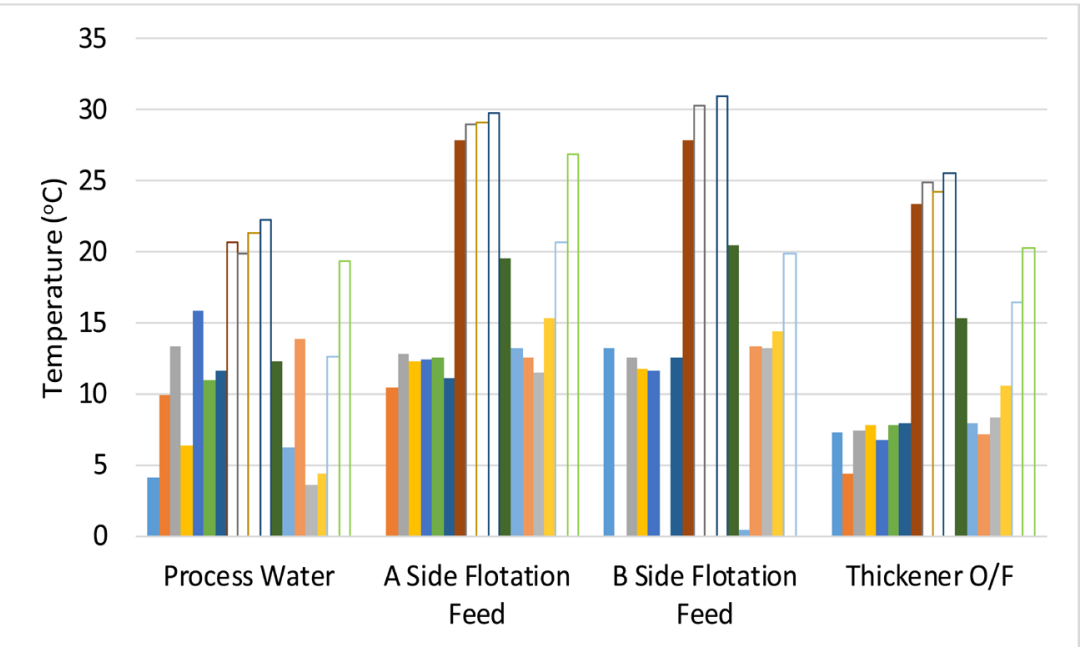

Figure 3. Temperature for process water, side A and side B flotation feeds and thickener overflow from November 2017 to June 2019. A side flotation was not sampled on November 23, 2017. B side flotation feed was not sampled on January 4, 2018, March 2, 2018, July 31, 2018 and June 25, 2019.

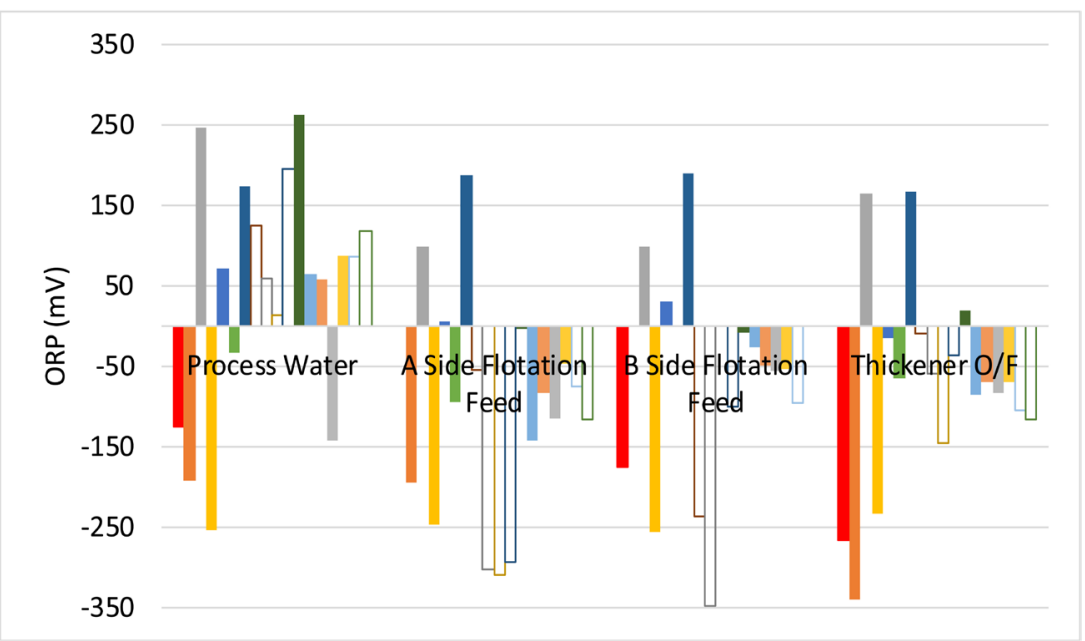

Figure 4. ORP for process water, side A and side B flotation feeds and thickener overflow from November 2017 to June 2019. A side flotation was not sampled on November 23, 2017. B side flotation feed was not sampled on January 4, 2018, March 2, 2018, July 31, 2018 and June 25, 2019.

Figures 2-4 illustrate the $\mathrm{pH}$, temperature, and oxidation reduction potential (ORP) for the sampling campaigns from November 2017 to June 15, 2019, respectively. These measurements were made on the pulp prior to filtering.

The process water came from the tailings treatment system (this is clean water); therefore, the $\mathrm{pH}$ of this stream tended to be between 6 and 9 with one survey at $\mathrm{pH} 10 . \mathrm{A} \mathrm{pH}$ of 10 typically does not occur. The thickener overflow stream had the highest $\mathrm{pH}$ and ranged from approximately 10 to 12 . The thickener overflow, receives water from the fines thickener, nickel concentrate, and copper thickener overflows. The fines thickener overflow was alkaline because it thickens the fines obtained at alkaline $\mathrm{pH}$. Nickel-copper separation is per- 
formed at $\mathrm{pH} \mathrm{12;} \mathrm{thus,} \mathrm{the} \mathrm{nickel} \mathrm{and} \mathrm{copper} \mathrm{concentrates} \mathrm{were} \mathrm{highly} \mathrm{alkaline.}$ Therefore, when the overflows of the copper and nickel concentrate thickeners and fines thickener were combined, the feed to the thickener overflow became alkaline. The process water and thickener overflow generally had lower temperature relative to the flotation feeds. This is to be expected because the water and ore were heated during grinding prior to flotation. Generally, the flotation feeds and the thickener overflow tended to have reducing pulp potentials. The low ORP may be caused by oxidation processes in the water and pulp [6]. Also, changes in the ore treated (different ratios of pentlandite, chalcopyrite and pyrrhotite in the ore) and water chemistry can cause variations in the ORP.

The filtrates for sulphate analysis of the sampled streams were frozen until assaying. When these were thawed (prior to analysis or assaying), white precipitates formed. To determine what these precipitates were, A side flotation feed and thickener feed \#3 samples were filtered then the solids were dried and weighed followed by XRD analysis. Figure 5 shows the XRD (Rigaku, model Dmax 2500) analysis of the precipitates for the flotation feed side A only. The $\mathrm{XRD}$ analysis showed that the precipitates were gypsum. The results of the XRD analysis of the precipitates for the thickener \#3 feed also confirmed that the

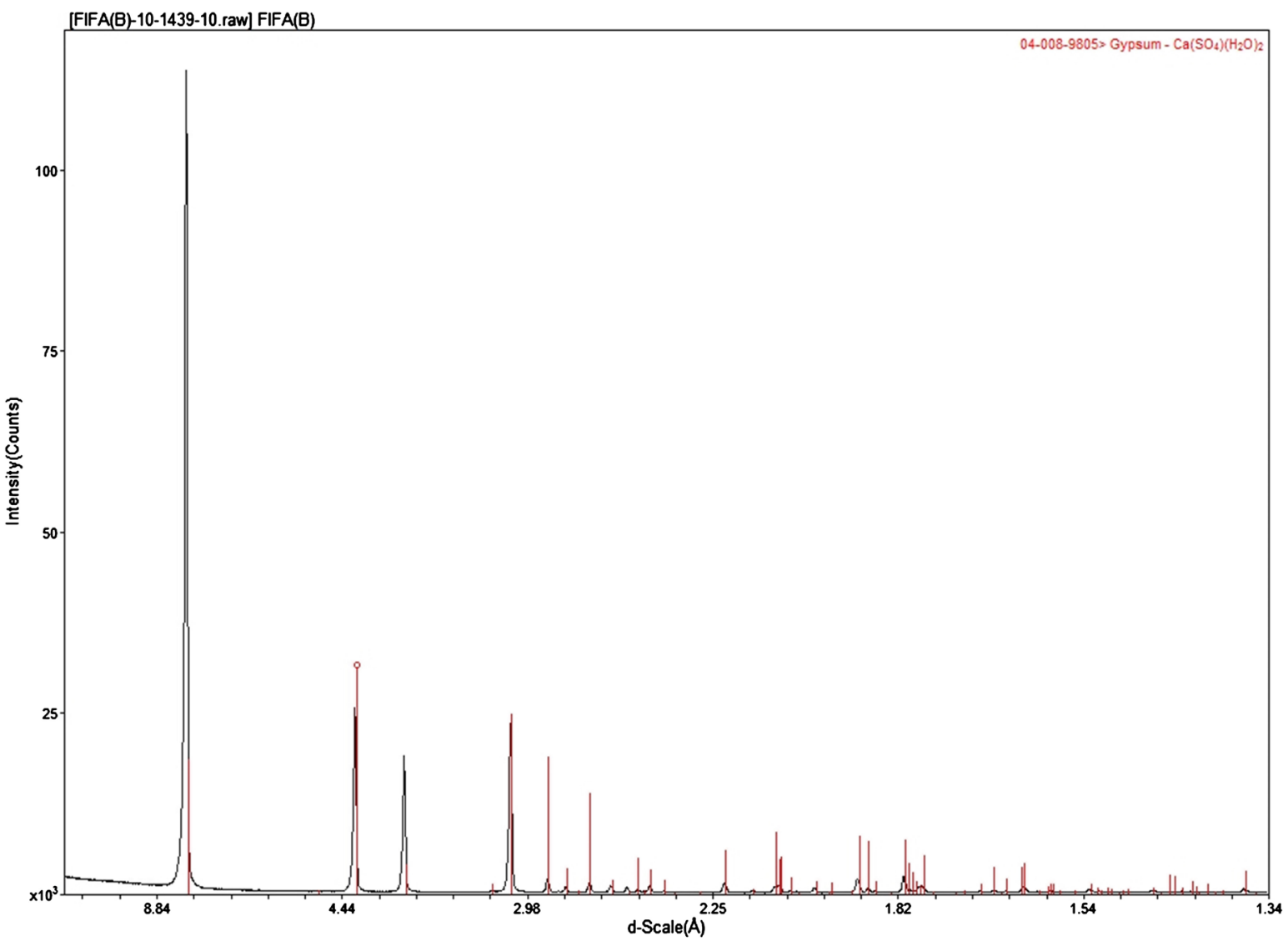

CANMET

Figure 5. XRD analysis of flotation feed side A gypsum precipitates. 
white solids were gypsum precipitates (results not shown). Based on the masses, there were approximately 500 to $550 \mathrm{ppm}$ of sulphate that precipitated from solution. Therefore, in Figure 7, Figure 9, Figure 11, and Figure 13 the sulphate concentrations are actually about 500 to $550 \mathrm{ppm}$ higher.

Figures 6-13 illustrate the inorganic species concentrations for the process water, side A flotation feed, side B flotation feed, and thickener overflow streams. Figures 14-17 show the total inorganic carbon (TIC), total organic carbon (TOC) and total carbon (TC). The sampling dates are shown in Table 3. Generally, for all the streams and species, there are no trends between the seasons. However, in some campaigns, there were peaks in concentration of species such as in Figure 14 and Figure 15. These peaks in total organic carbon and total carbon may have been caused by higher collector and frother dosages in the flotation circuit. The thickener overflow that the concentrator would like to increase the amount recirculated, had higher concentrations of total inorganic

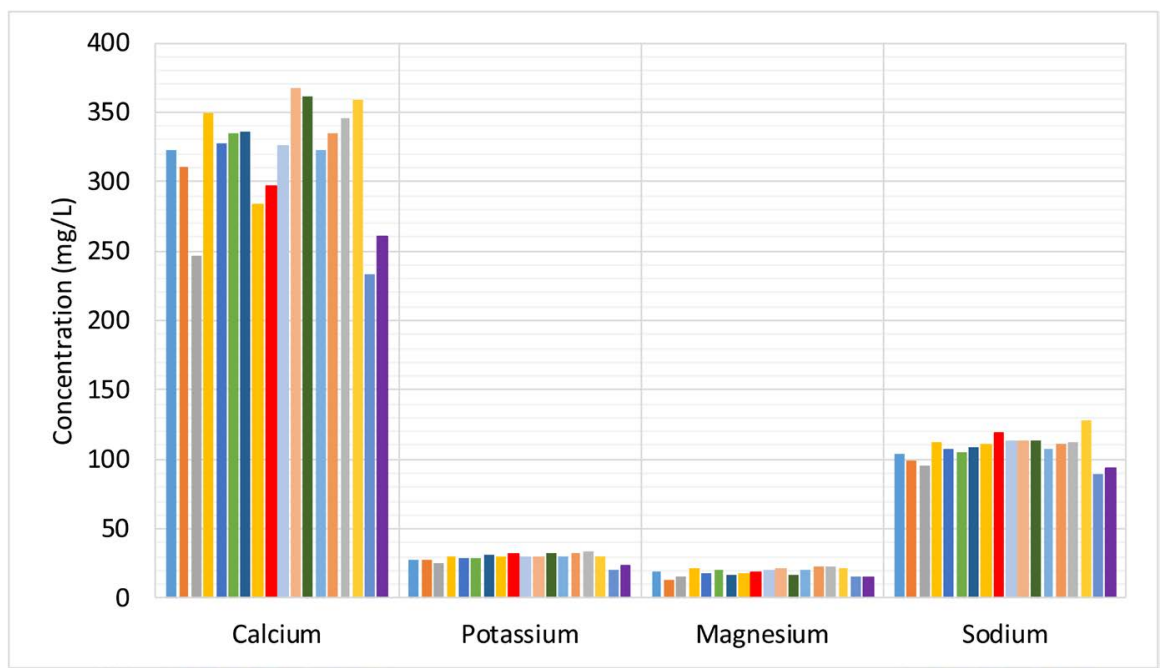

Figure 6. Process water chemistry from November 2017 to June 2019.

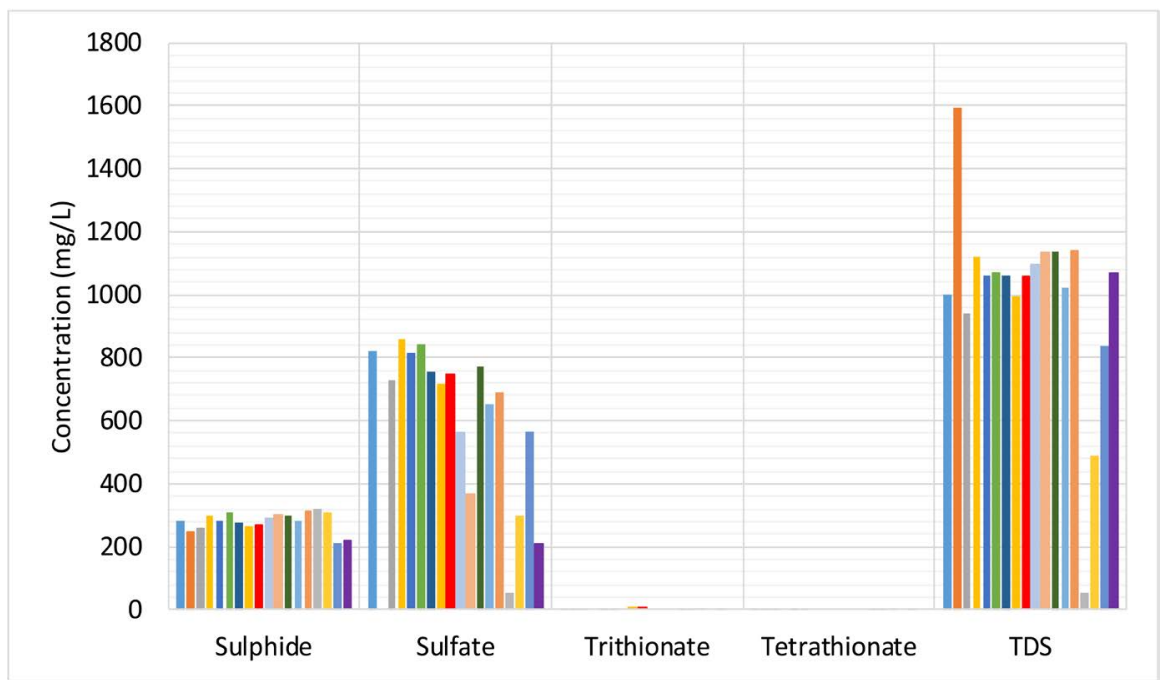

Figure 7. Process water chemistry from November 2017 to June 2019. 


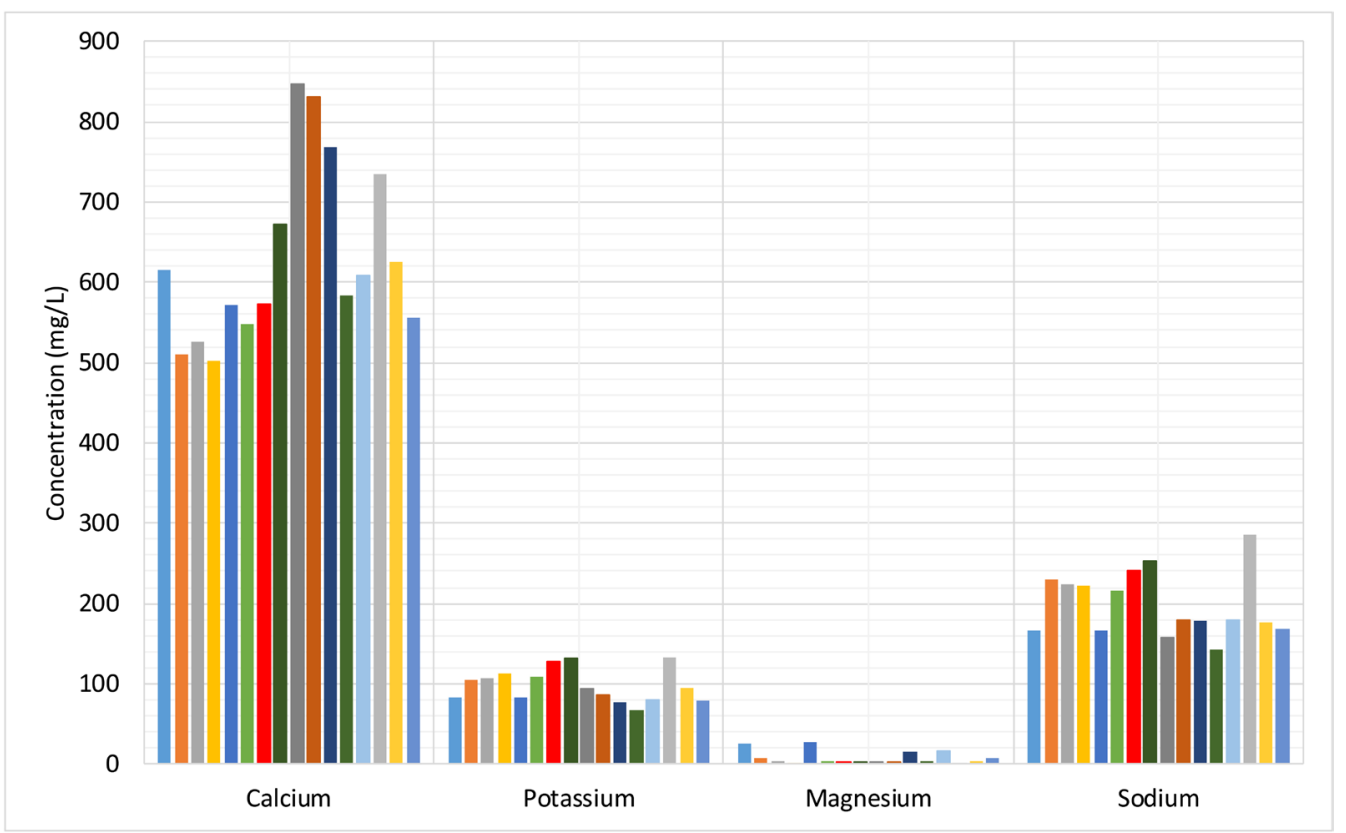

Figure 8. Flotation feed side A chemistry from January 2018 to June 2019 (November 23, 2017, the stream was not sampled).

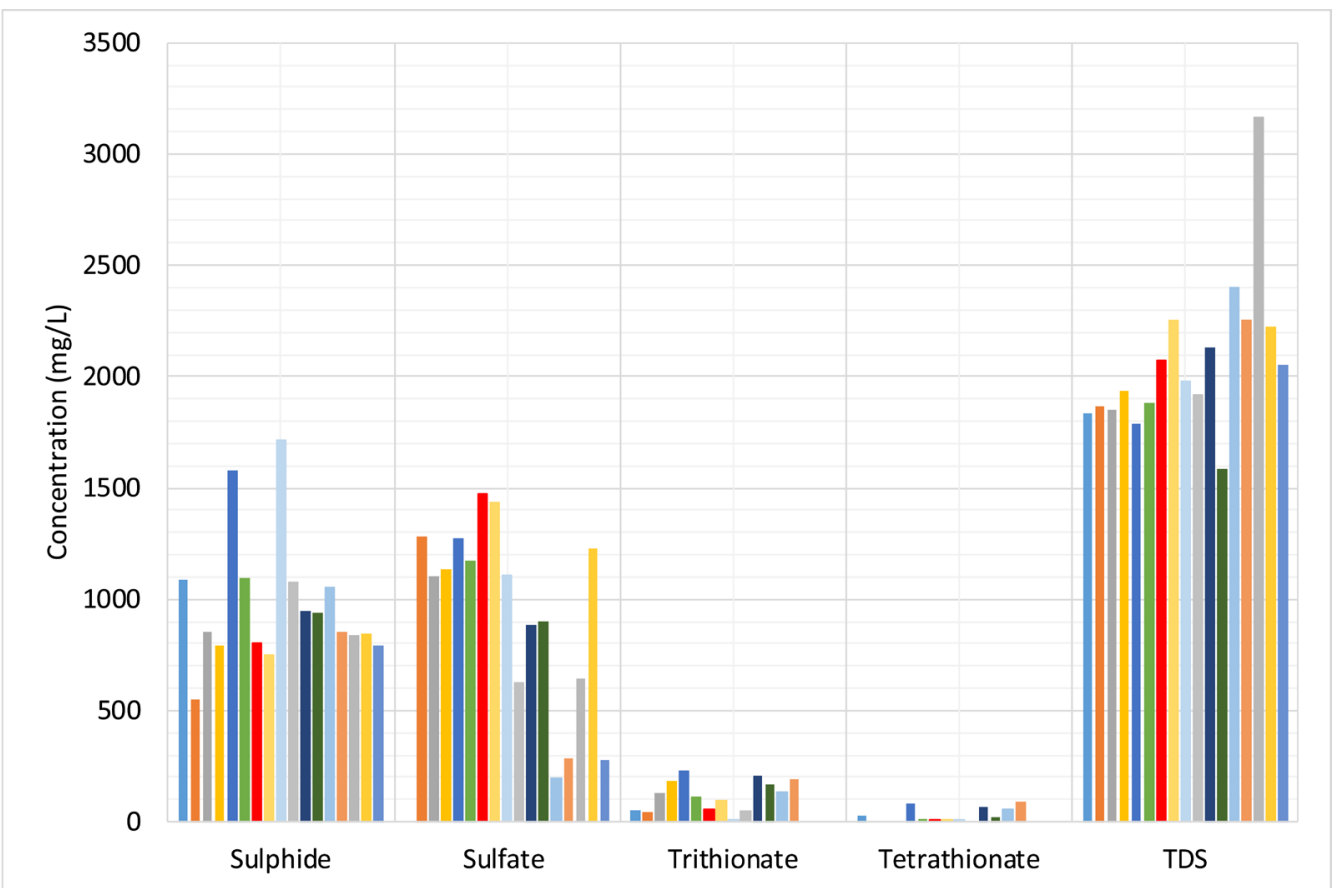

Figure 9. Flotation feed side A chemistry from January 2018 to June 2019 (November 23, 2017, the stream was not sampled).

carbon (TIC), total organic carbon (TOC), total carbon TC and total dissolved solids (TDS) than those of the process water. The higher TC and TDS can have significant impacts on flotation [1]. For example, accidental activation of undesired minerals, increased gangue recovery through entrainment, slime coating, passivation of valuable minerals, etc [1]. Therefore, water treatment may have to 


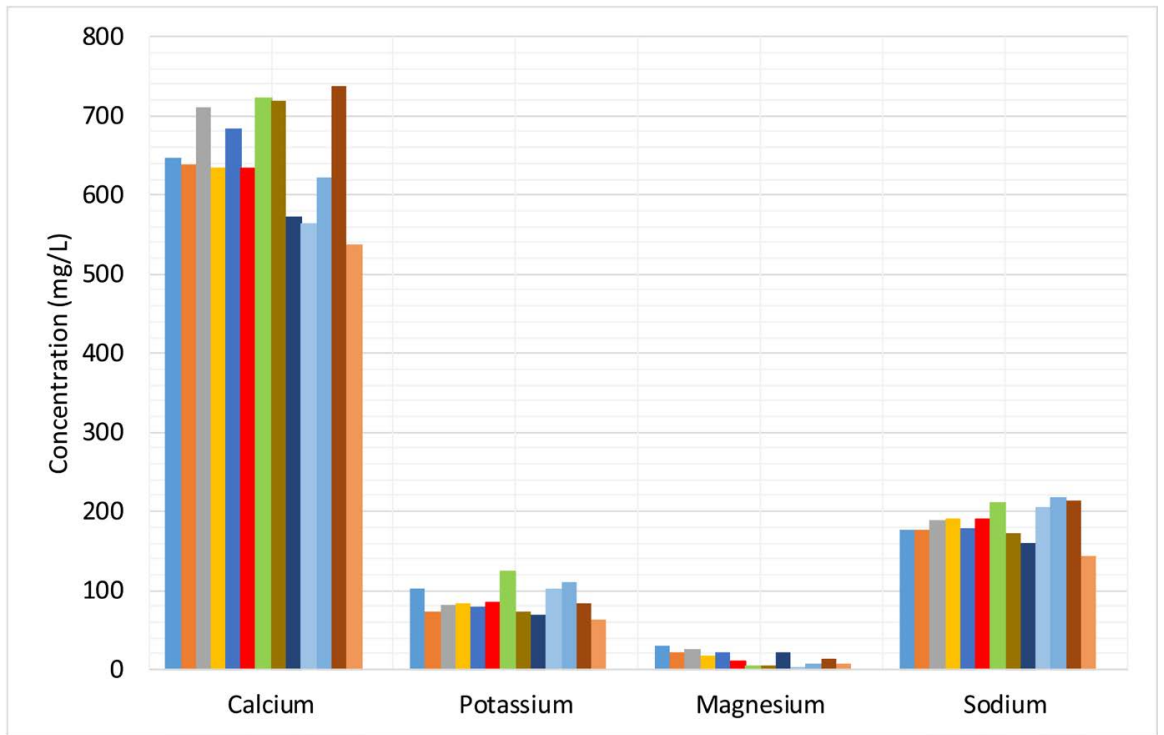

Figure 10. Flotation feed side B chemistry from November 2017 to May 2019 (January 4, 2018, March 2, 2018, July 31, 2018 and June 25, 2019 the flotation side B was not sampled).

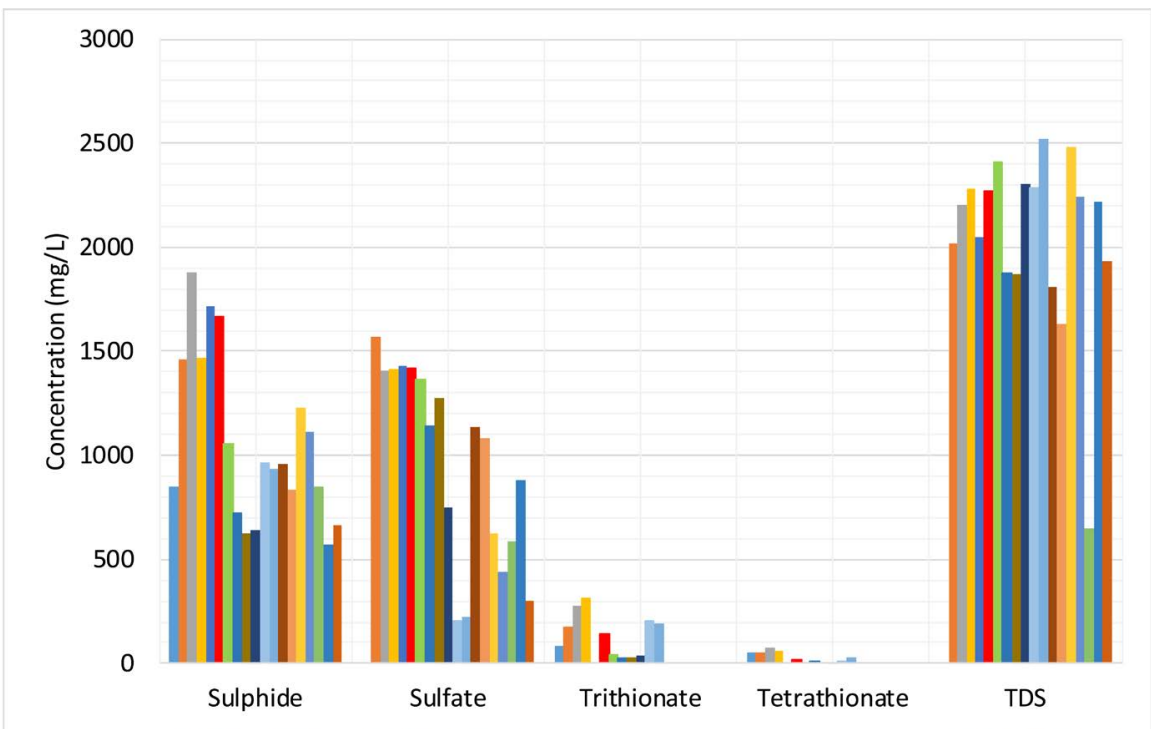

Figure 11. Flotation feed side B chemistry from November 2017 to May 2019 (January 4, 2018, March 2, 2018, July 31, 2018 and June 25, 2019 the flotation side B was not sampled).

be employed to reduce the TC and TDS prior to recirculation. This is beyond the scope of this publication.

The average \%solids of the campaigns for the process water, thickener overflow, side A flotation feed and side B flotation feed were $0.10 \%, 0.11 \%, 48.11 \%$ and $46.56 \%$, respectively. The suspended solids in the thickener overflow were assayed.

Figure 18 shows the assays of the suspended solids in the thickener overflow stream for the dates indicated in Table 3 except for the August 2018 campaign; the solids were not assayed due to lack of sample. The nickel and copper grades can be as high as approximately $5 \%$ and $10 \%$, respectively. At an average volumetric 


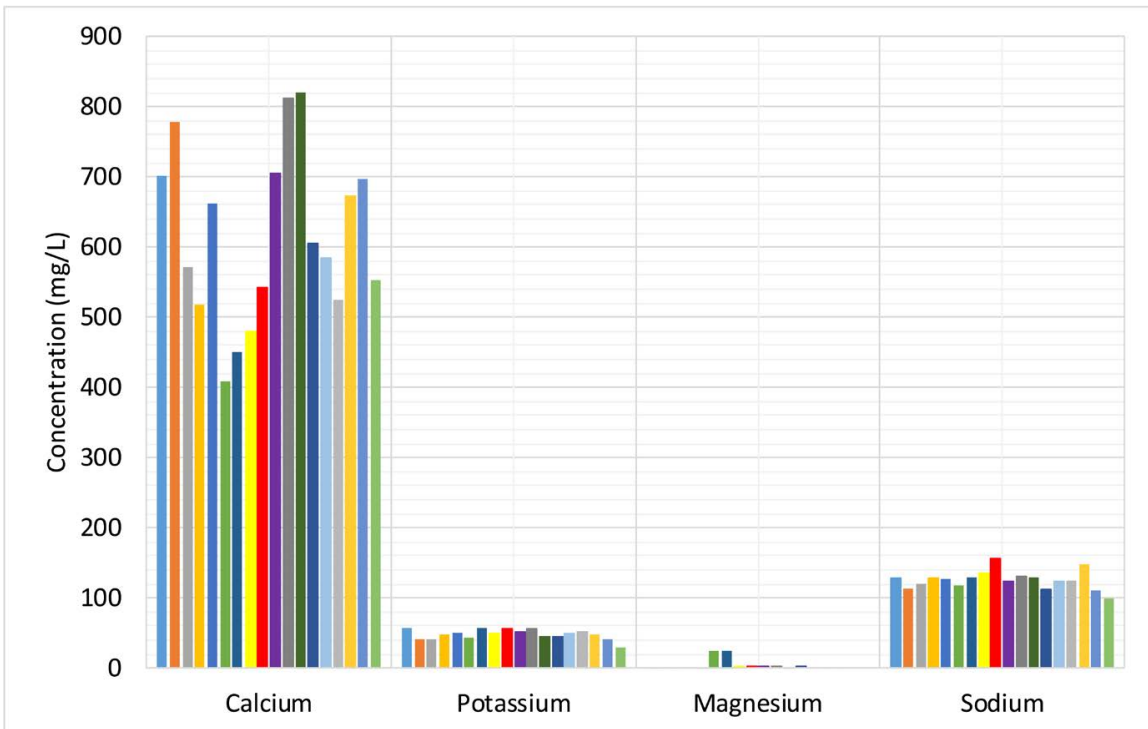

Figure 12. Thickener overflow chemistry from November 2017 to June 2019.

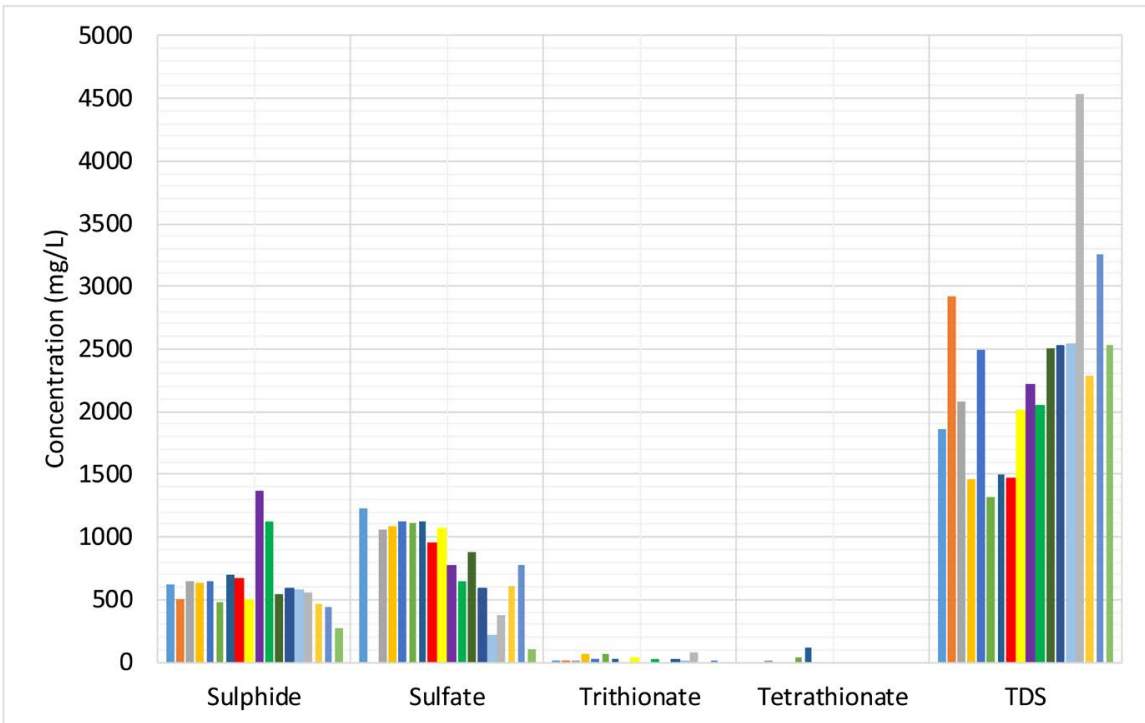

Figure 13. Thickener overflow chemistry from November 2017 to June 2019.

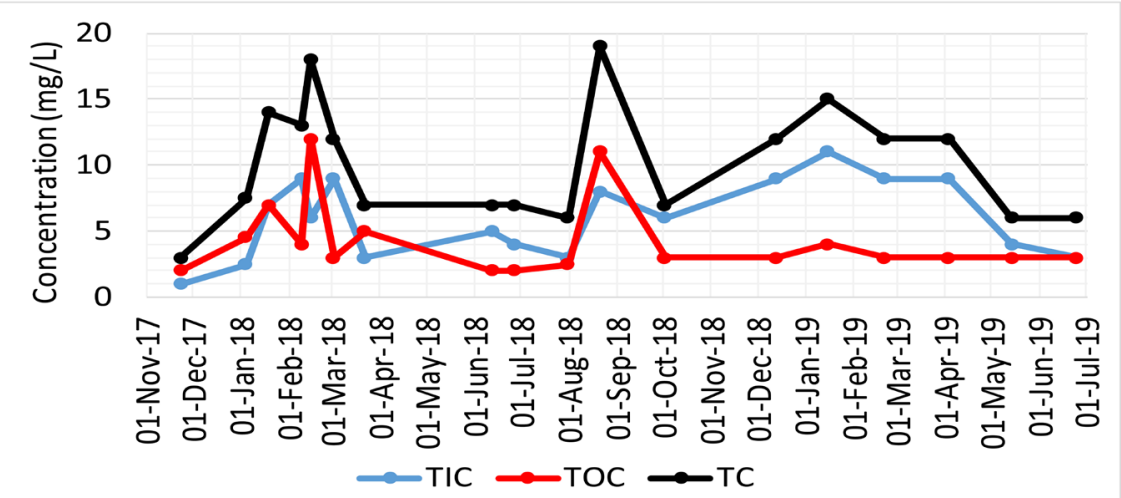

Figure 14. Total inorganic, total organic and total carbon (TC) concentrations for process water from November 2017 to June 2019. 


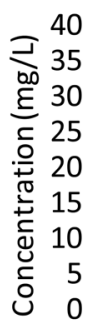

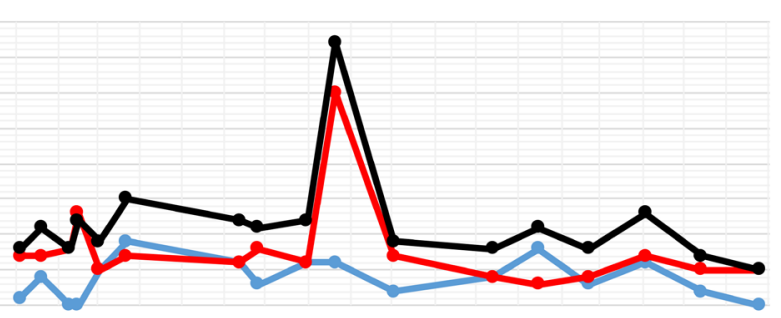

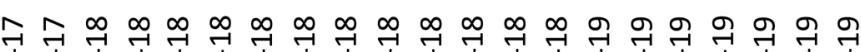

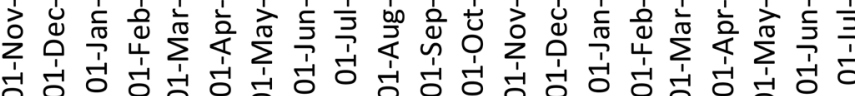

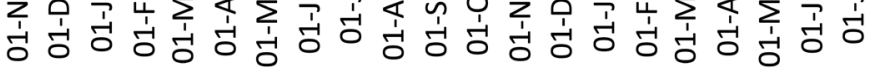

$$
\because \text { TIC } \rightarrow \text { TOC } \rightarrow \text { TC }
$$

Figure 15. Total inorganic, total organic and total carbon (TC) concentrations for A side flotation feed from January 2018 to June 2019 (for November 23, 2017 the stream was not sampled).

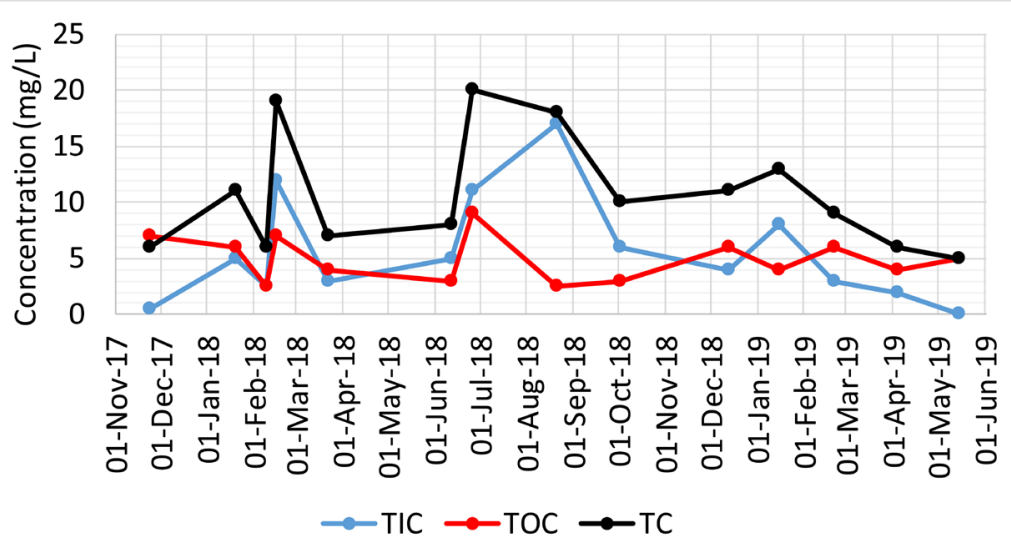

Figure 16. Total inorganic, total organic and total carbon (TC) concentrations for flotation feed side B from November 2017 to May 2019 (January 4, 2018 and June 25, 2019 the flotation side B was not sampled).

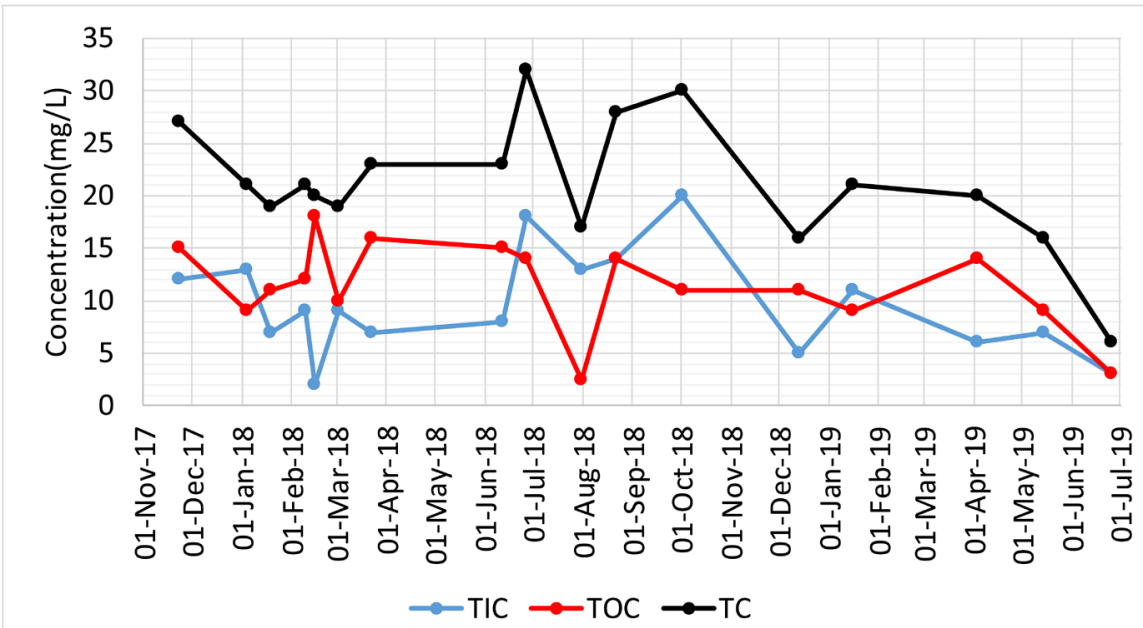

Figure 17. Total inorganic, total organic and total carbon (TC) concentrations for thickener overflow from November 2017 to June 2019. 


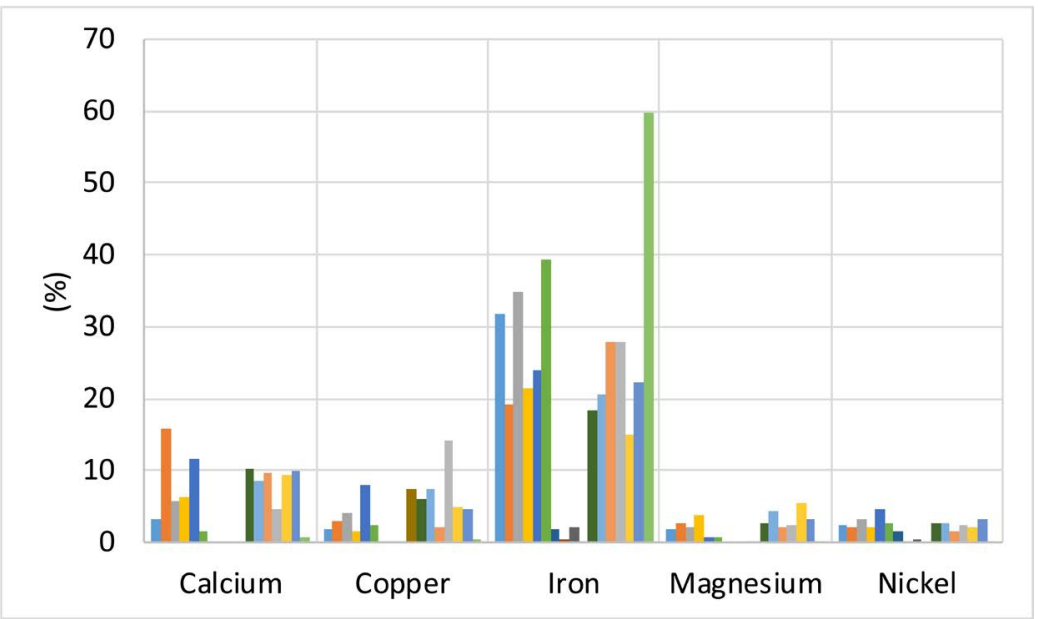

Figure 18. Assay Results of thickener overflow solids from November 2017 to June 2019 (August 2018 campaign the solids were not assayed due to lack of sample).

flowrate of the thickener overflow stream of approximately $124 \mathrm{~m}^{3} / \mathrm{hr}$, this represents a notable amount ( 1.5 tonnes/day) of paymetal (nickel and copper) going back to the grinding circuit where it is combined with process water.

Another observation worth noting is the concentration of calcium in the solids. For some campaigns, the \% calcium in the solids was almost as high as $20 \%$. Scaling is already an issue at the concentrator and if the quantity of thickener overflow is increased, scaling most likely will become worse. The implication is more frequent shutdowns to clean or replace the piping, which would have a significant financial impact. The recommended next step is to carry out water treatment tests in the future to determine the conditions that would allow the reduction or elimination of calcium precipitate.

Figure 19 shows the particle size distribution of the solids suspended in the thickener overflow. The $80 \%$ passing of the suspended solids was approximately 75 micrometers. These solids should be liberated because the feed size to flotation is $56 \%$ passing 75 micrometers. If these solids are ground further, fines will be produced and most likely will be lost in the final tailings. Therefore, filtering this stream and sending the solids directly to copper-nickel separation in the flotation circuit will increase the copper and nickel recoveries to final copper and final nickel concentrates, respectively.

Figure 20 illustrates the total DNA concentration in raw extracts from the process water. The DNA for side A flotation feed, side B flotation feed and thickener overflow were measured and found to be negligible. The dates for Figure 20 are shown in Table 3. For the process water stream, DNA concentration ranged from 27 to $6800 \mathrm{ng} / \mathrm{mL}$ and displayed a clear seasonal effect, with the greatest amounts of extractable DNA being measured in the warmer months and little to none detected in the winter months. The thickener overflow yielded $12.8 \mathrm{ng} / \mathrm{mL}$ in the August 2018 sampling campaign, which is not shown in Figure 20. At no other time was extractable DNA measured in the thickener overflow. Likewise, no extractable DNA was measured in either of the side A or side 


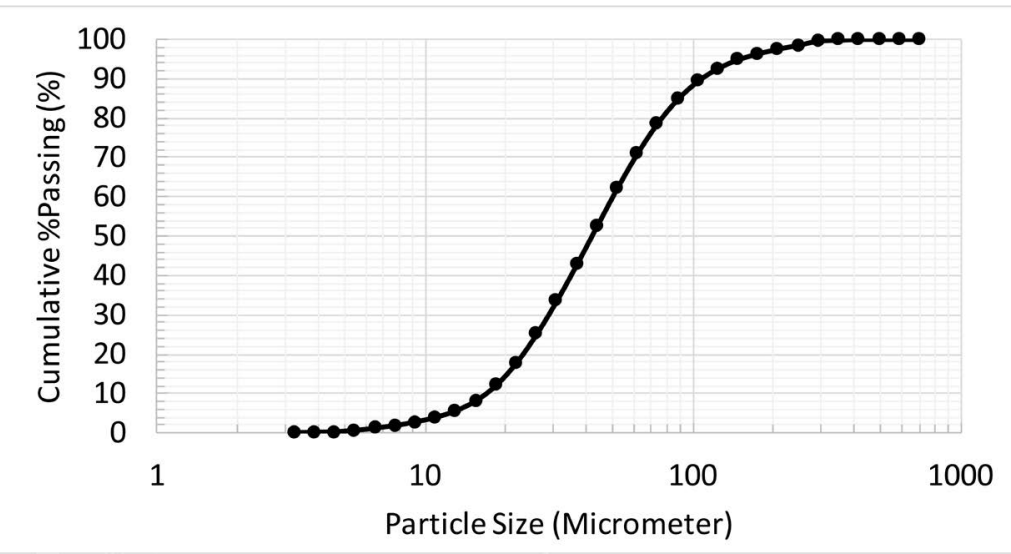

Figure 19. Typical particle size distribution of the solids in the thickener overflow.

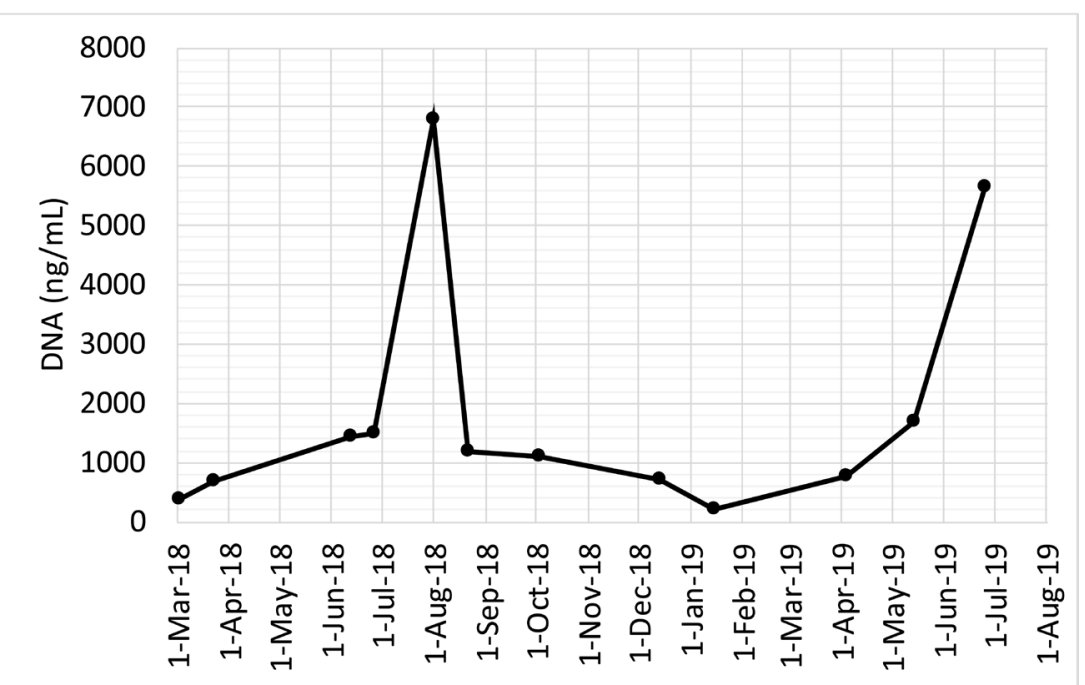

Figure 20. Concentrations of total DNA in extracts from process water from November 2017 to June 2019 (November 2017 and February 21, 2019, there was not enough sample).

B flotation feed samples. It is important to note that the DNA concentrations in the unprocessed water samples would be several orders of magnitude lower than in the extracts reported here. Microbial cells can cause significant changes in the surrounding water chemistry, particularly with respect to $\mathrm{pH}$ and ORP and can metabolize certain flotation additives, all of which could have serious effects on mineral flotation. The effects of microbial cells on flotation will be investigated in a subsequent paper.

\subsection{Flotation Testing}

In the plant, the rougher circuit consists of the primary rougher, secondary rougher and scavenger. The primary rougher concentrate goes directly to copper-nickel separation. Therefore, the nickel + copper grade of this concentrate is important because it influences the final copper and final nickel concentrate grades. If the primary rougher concentrate grade is too low, then the final copper and final nickel concentrates grade specifications may not be met. 
Process water and thickener overflow were received in April 2019, June 2019, and August 2019 from the concentrator. The flotation tests were done using the water ratios shown in Table 2. The water samples were stored in a refrigerator until further use [10]. Also, a weighted average was computed for the metallurgical results.

\subsubsection{Plant Water-April 2019}

Figure 21 shows the nickel + copper grade versus nickel recovery for the water types. The nickel + copper grade versus nickel recovery decreased as the amount of thickener overflow used increased. The reasons will be discussed shortly.

The second point on the grade-recovery curve represents the primary concentrate. The nickel + copper grade of the primary rougher concentrate decreased in the presence of thickener overflow. Laboratory copper-nickel separation tests using thickener overflow are recommended to ensure that there are no negative impacts on final concentrate grades.

The pyrrhotite recovery versus pentlandite recovery and gangue recovery versus pentlandite recovery selectivity curves are shown in Figure 22 and Figure 23 , respectively. The reduction in the nickel + copper grade versus nickel recovery curves when thickener overflow was used was due to higher pyrrhotite (Po)

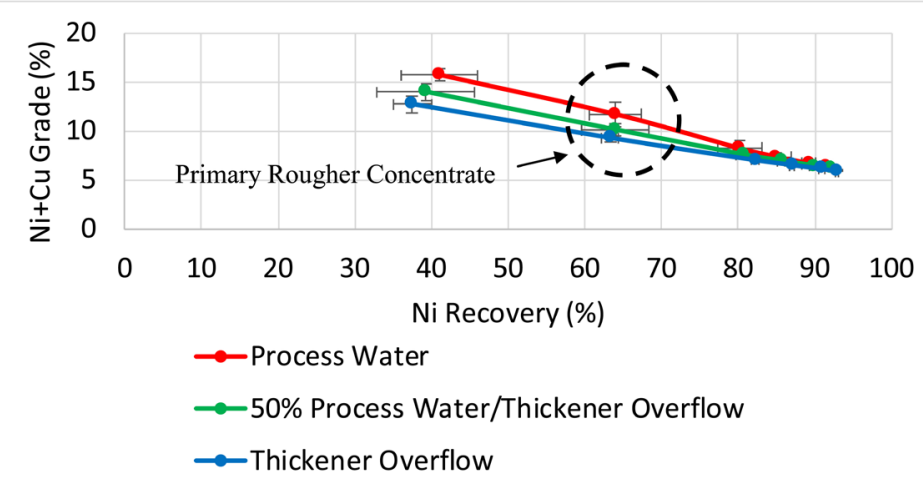

Figure 21. Nickel + copper grade versus nickel recovery-April 2019.

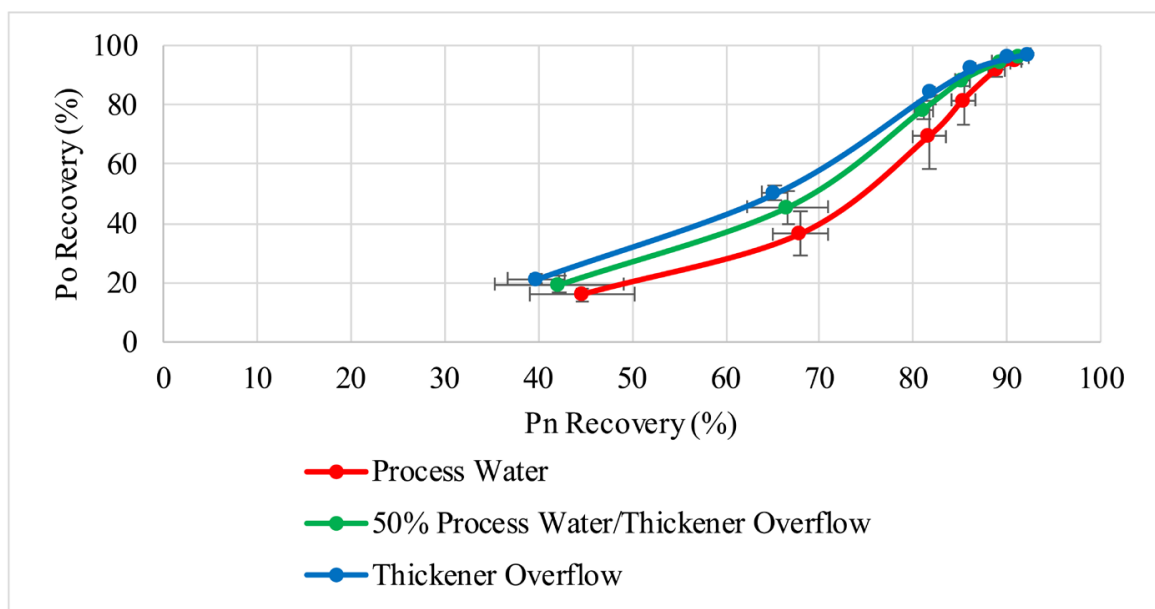

Figure 22. Pyrrhotite versus pentlandite recovery-April 2019. 


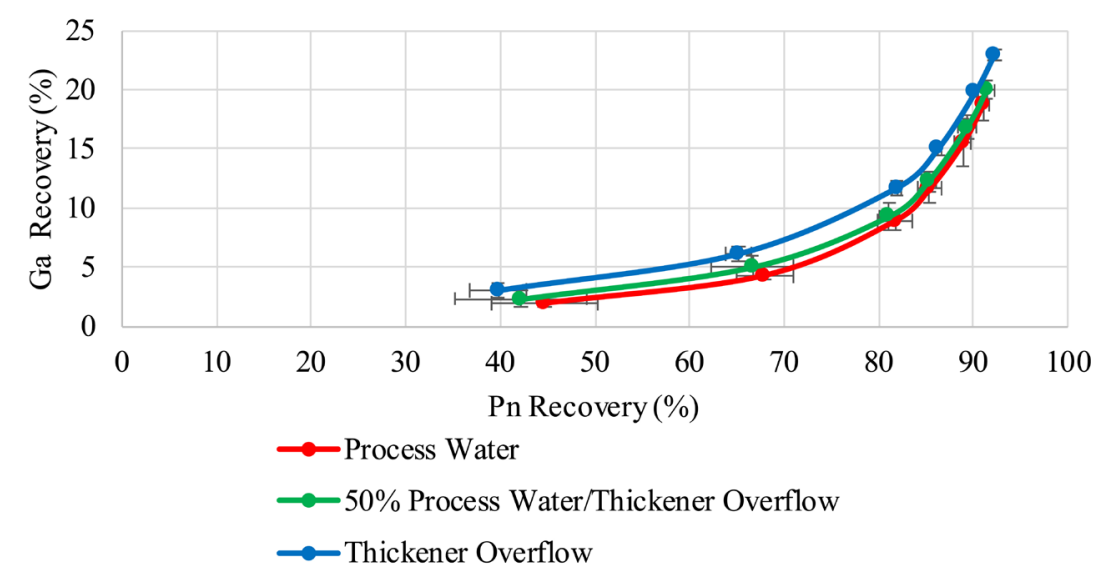

Figure 23. Gangue versus pentlandite recovery-April 2019.

and gangue $(\mathrm{Ga})$ recoveries. Both the pyrrhotite and gangues recoveries increased in the presence of the thickener overflow.

Figure 24 and Figure 25 show the pyrrhotite recovery versus water recovery and gangue recovery versus water recovery, respectively. For pyrrhotite, the relationship is not a straight line, which means entrainment was not the main recovery mechanism. The gangue recovery versus water recovery for the water types was fairly linear, which means that the main recovery mechanism for gangue was by entrainment. When thickener overflow was used, the gangue recovery by entrainment was higher relative to the other water types, which is most likely one of the reasons for higher gangue recovery observed in Figure 23. However, accidental activation may be another cause for higher gangue recovery; this will be discussed later in the publication.

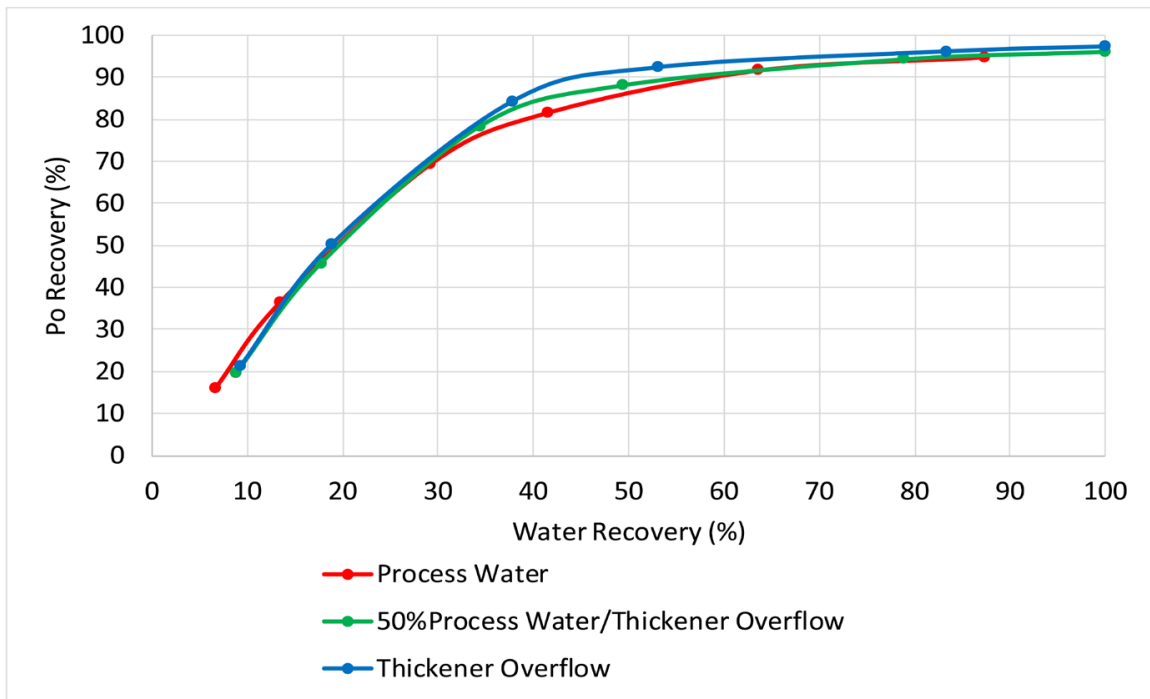

Figure 24. Pyrrhotite Recovery versus Water Recovery-April 2019.

A statistical analysis (MANOVA) was done on the nickel and copper recoveries to determine whether the utilisation of thickener overflow had a negative 
impact on these parameters. The MANOVA analysis was performed using the parameters days (blocks) and water ratio. Since two parameters were used, an $\alpha$ of 0.025 ( $\alpha=0.05 / 2=0.025$ - Bonferroni adjustment) was used for the significance testing for both the days (blocks) and water ratio.

Table 4 shows the results of the MANOVA analysis for the days (blocks). For the day or block parameter, all the probabilities for the four different test statistics applied were greater than 0.025 so we cannot reject the null hypothesis that the nickel and copper recoveries between the days (blocks) were the same. This means that the nickel and copper recoveries were not affected by the water chemistry differences, if any, between the days the flotation tests were done.

Figure 26 shows the chemistry of the water types for the three days of testing. For all the species, the concentrations for the same water types between the days were approximately the same, thus, this is consistent with the conclusion that the days (blocks) were not significant or did not affect the metallurgy.

Table 5 illustrates the results of the MANOVA analysis of the effect of water ratio on nickel and copper recoveries. All the probabilities for the test statistics were less than 0.025 with the exception of the Hotelling-Lawley Trace test. Since three out of the four test statistics were significant, we can reject the null hypothesis that the nickel and copper recoveries were the same. This implies that at least one of the water types had a significant effect (at 95\% level) on nickel

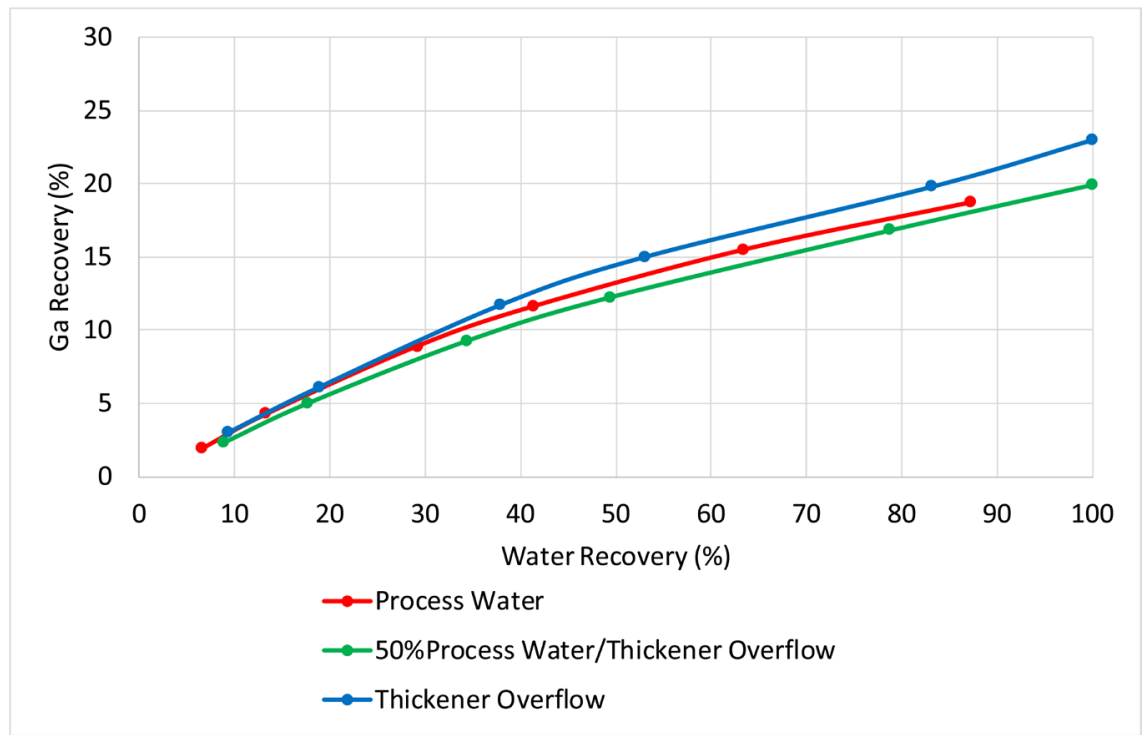

Figure 25. Gangue recovery versus water recovery_April 2019.

Table 4. Test Statistics for the blocks or days-April 2019.

\begin{tabular}{cc}
\hline Test Statistic & $\mathrm{p}$ value $(\operatorname{Pr}>\mathrm{F})$ \\
\hline Wilks' Lambda & 0.1923 \\
Pillai's Trace & 0.2089 \\
Hotelling-Lawley Trace & 0.1825 \\
Roy's Greatest Root & 0.0416 \\
\hline
\end{tabular}




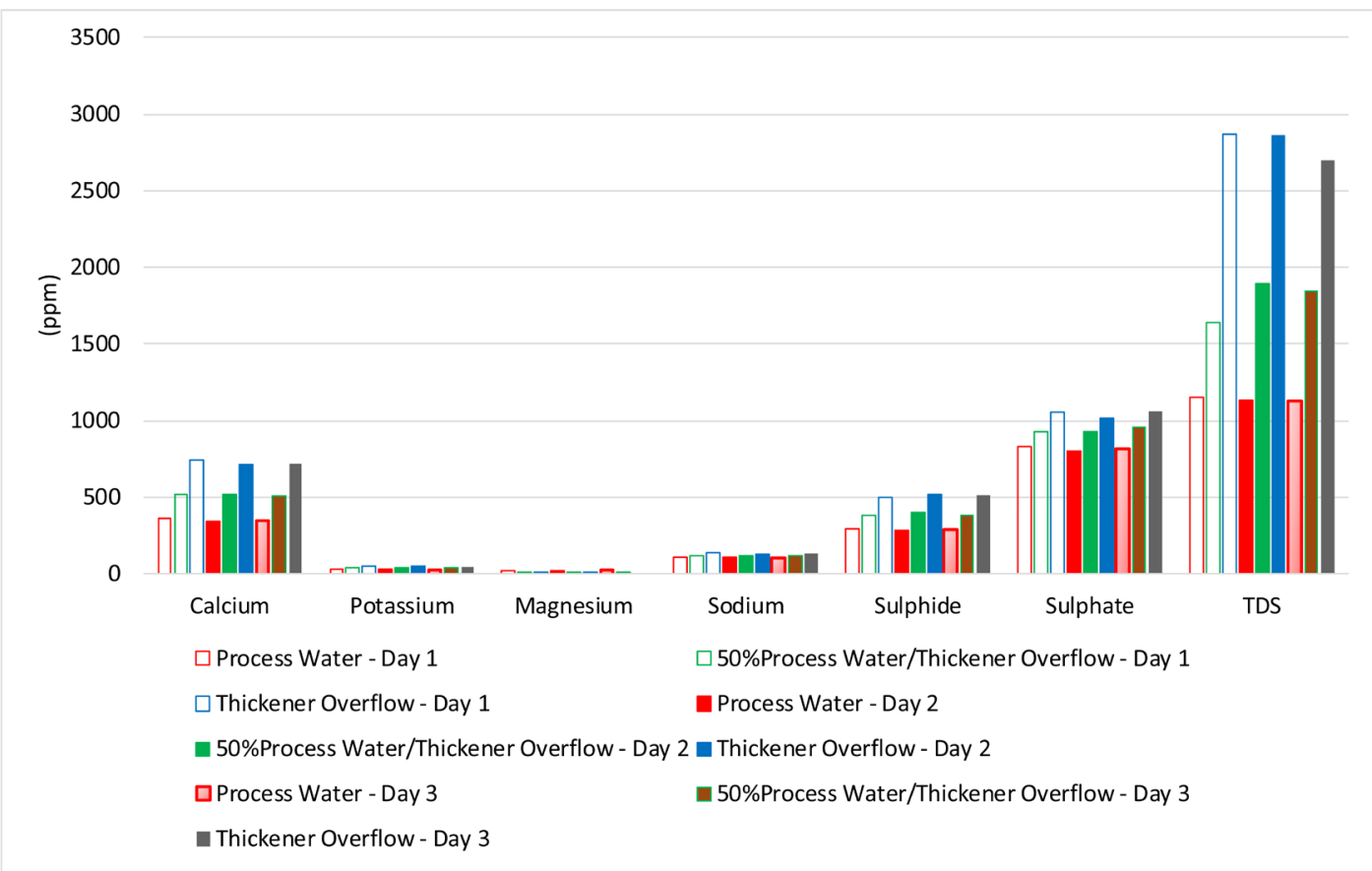

Figure 26. Species concentration in process water, $50 \%$ process water $/ 50 \%$ thickener overflow and thickener overflow-April 2019.

Table 5. Test statistics for the effect of water ratio-April 2019.

\begin{tabular}{cc}
\hline Test Statistic & $\mathrm{p}$ value $(\mathrm{Pr}>\mathrm{F})$ \\
\hline Wilks' Lambda & 0.0146 \\
Pillai's Trace & 0.0238 \\
Hotelling-Lawley Trace & 0.0255 \\
Roy's Greatest Root & 0.0026 \\
\hline
\end{tabular}

and/or copper recovery.

In order to determine which water type had a significant impact on nickel and/or copper recovery, the contrast method in MANOVA analysis was used. Tables 6-8 show the results of this analysis. Since three comparisons are made (3 water types), the significance level $\alpha$ is divided by three to make the Bonferroni adjustment for the significance testing. Hence, the significance levels for the test statistics will be compared to a significance level $\alpha=0.05 / 3=0.017$. The only significant comparison was process water versus thickener overflow $(\mathrm{p}<0.017$ for all the test statistics). Hence, we can reject the null hypothesis that the nickel and/or copper recoveries were the same. In order to determine whether nickel recovery and/or copper recovery were significantly different between those obtained with process water and thickener overflow, the ANOVA portion of the output of the analysis was used (the MANOVA analysis also produces an ANOVA output to determine which recovery difference was significant). The ANOVA output will be discussed shortly.

Table 9 shows the ANOVA portion of the MANOVA analysis for nickel and 
Table 6. Test statistic for process water versus 50\% process water $/ 50 \%$ thickener overflow-April 2019.

\begin{tabular}{cc}
\hline Test Statistic & $\mathrm{p}$ value $(\operatorname{Pr}>\mathrm{F})$ \\
\hline Wilks' Lambda & 0.0583 \\
Pillai's Trace & 0.0583 \\
Hotelling-Lawley Trace & 0.0583 \\
Roy's Greatest Root & 0.0583 \\
\hline
\end{tabular}

Table 7. Test statistic for process water versus thickener overflow-April 2019.

\begin{tabular}{cc}
\hline Test Statistic & $\mathrm{p}$ value $(\mathrm{Pr}>\mathrm{F})$ \\
\hline Wilks' Lambda & 0.0114 \\
Pillai's Trace & 0.0114 \\
Hotelling-Lawley Trace & 0.0114 \\
Roy's Greatest Root & 0.0114 \\
\hline
\end{tabular}

Table 8. Test statistic for $50 \%$ process water $/ 50 \%$ thickener overflow versus thickener overflow-April 2019.

\begin{tabular}{cc}
\hline Test Statistic & $\mathrm{p}$ value $(\mathrm{Pr}>\mathrm{F})$ \\
\hline Wilks' Lambda & 0.0652 \\
Pillai's Trace & 0.0652 \\
Hotelling-Lawley Trace & 0.0652 \\
Roy's Greatest Root & 0.0652 \\
\hline
\end{tabular}

Table 9. ANOVA output (from MANOVA analysis) for nickel recovery-April 2019.

\begin{tabular}{ccc}
\hline Contrast & $\begin{array}{c}\text { Ni Recovery- } \\
\mathrm{p} \text { value }(\mathrm{Pr}>\mathrm{F})\end{array}$ & $\begin{array}{c}\text { Cu Recovery- } \\
\mathrm{p} \text { value }(\mathrm{Pr}>\mathrm{F})\end{array}$ \\
\hline $\begin{array}{c}\text { process water versus 50\% process water/50\% } \\
\text { thickener overflow }\end{array}$ & 0.0437 & 0.0097 \\
$\begin{array}{c}\text { process water versus thickener overflow } \\
\text { 50\% process water/50\% thickener overflow } \\
\text { versus thickener overflow }\end{array}$ & 0.0018 & 0.0010 \\
\hline
\end{tabular}

copper recoveries, respectively. Since we are comparing water types for nickel and copper recoveries (ANOVA), the Bonferroni adjustment would be 3 ( 3 comparisons) or significance level $\alpha$ of $0.05 / 3=0.017$. For nickel recovery, the process water versus thickener overflow and $50 \%$ process water $/ 50 \%$ thickener overflow versus thickener overflow for nickel were less than 0.017 ; thus, the differences in nickel recoveries between the two water types were significant. This implies that we can reject the null hypothesis that the nickel recoveries between the water types were the same. For copper recovery, process water versus 50\% process water $/ 50 \%$ thickener overflow, process water versus thickener overflow and $50 \%$ process water $/ 50 \%$ thickener overflow versus thickener overflow were 
less than or equal to 0.017 . Thus, we can reject the null hypothesis that the copper recoveries between the water types were the same and the differences in copper recoveries between the water types were significant.

Figure 27 shows the profile plot for the nickel and copper recoveries for the flotation tests conducted using the April 2019 plant water. The copper recoveries tended to be higher than those obtained for nickel. The highest nickel and copper recoveries were obtained with the tests conducted using thickener overflow and they were significant at $95 \%$ confidence level relative to the recoveries obtained with process water.

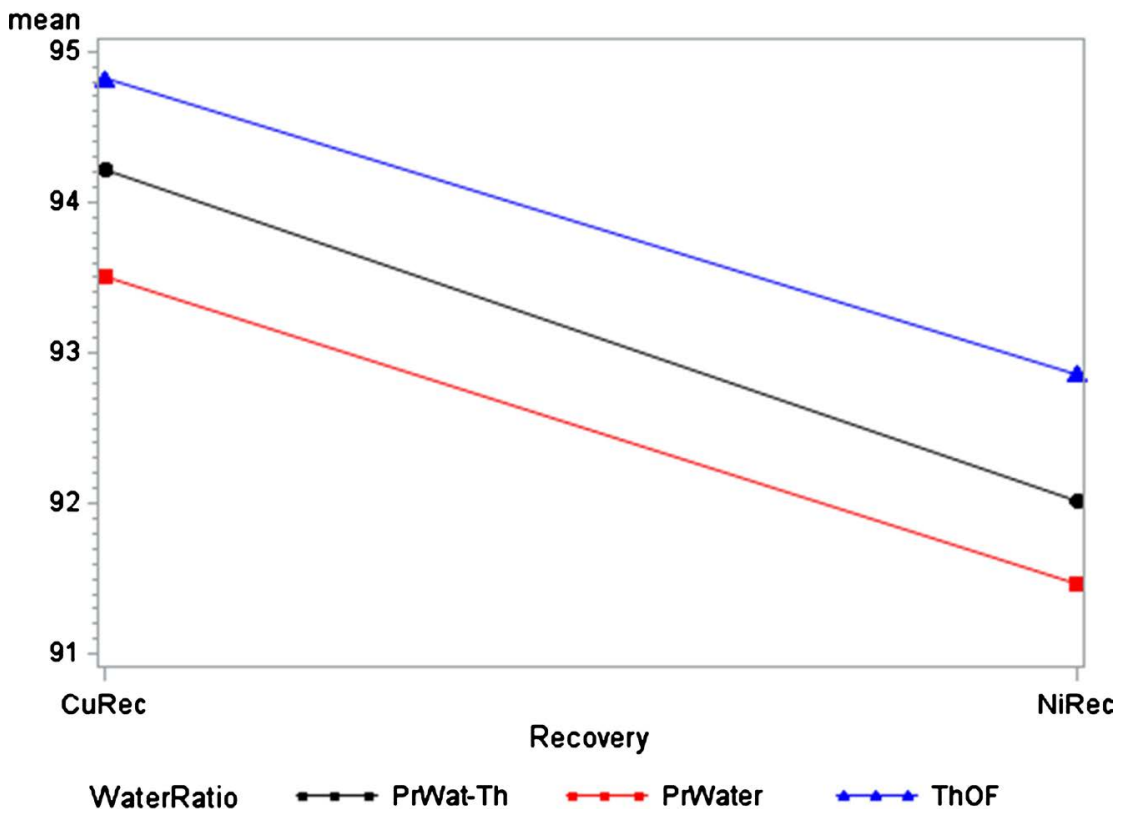

Figure 27. Profile Plot for nickel and copper recoveries for flotation tests completed using spring 2019 plant water (PrWater-Th: 50\% process water and 50\% thickener overflow, PrWater: process water, and ThOF: thickener overflow).

\subsubsection{Plant Water-June 2019}

Figure 28 illustrates the nickel + copper recovery versus nickel recovery for the process water and thickener overflow samples taken in June 2019. The flotation

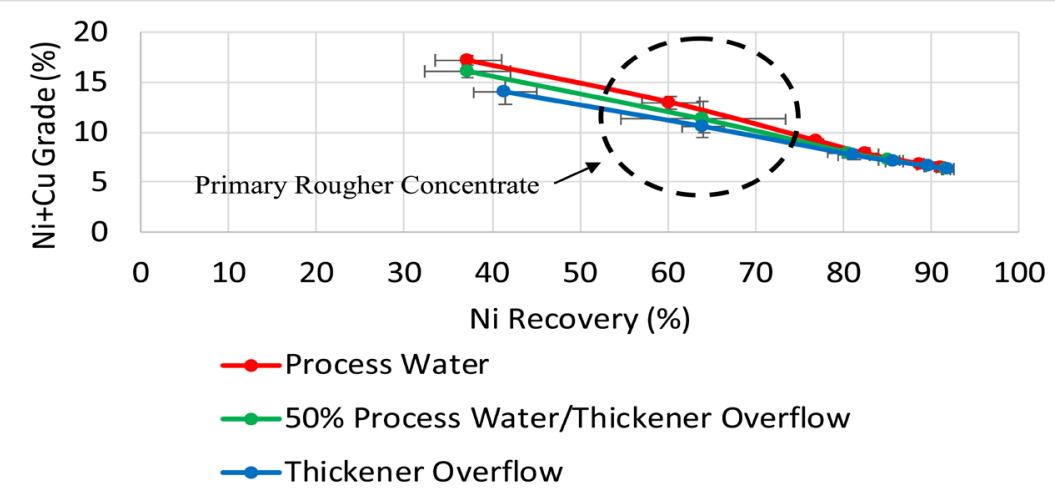

Figure 28. Nickel + copper grade versus nickel recovery-June 2019. 
tests conducted with thickener overflow only resulted in a lower nickel + copper grade versus nickel recovery curves. This decrease was significant at the $90 \%$ confidence level.

Figure 29 and Figure 30 show the pyrrhotite recovery versus pentlandite recovery and gangue recovery versus pentlandite recovery, respectively. The selectivity between pentlandite and pyrrhotite minerals decreased for thickener overflow only, which explains the lower nickel + copper grade versus nickel recovery for the tests conducted with the thickener overflow. The selectivity between gangue and pentlandite did not vary between the water types. Therefore, gangue in this case did not lower the nickel + copper grade in the primary and secondary rougher concentrates.

Figure 31 and Figure 32 show the pyrrhotite recovery versus water recovery and gangue recovery versus water recovery for the tests done using the plant water obtained in June 2019, respectively. The pyrrhotite recovery versus water recovery for the water types was not a linear relationship, which implies that the main recovery mechanism for pyrrhotite was by true flotation. The gangue recovery versus water recovery for the water types was almost a straight line; thus, the main recovery mechanism for gangue was by entrainment for all the water types.

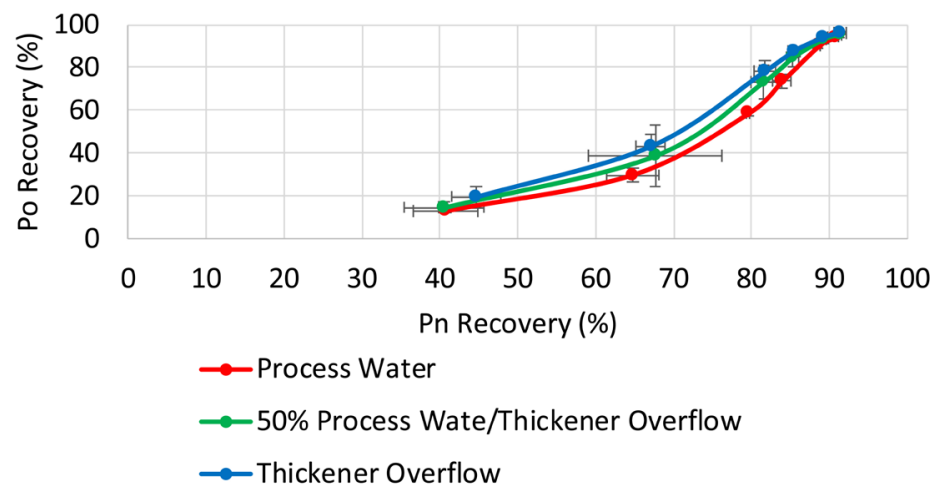

Figure 29. Pyrrhotite recovery versus pentlandite recovery-June 2019.

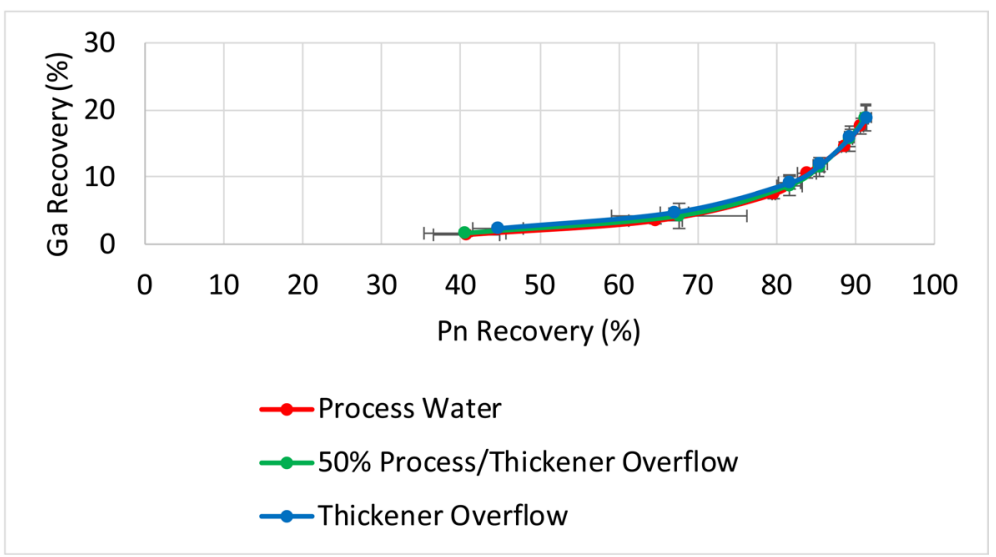

Figure 30. Gangue recovery versus pentlandite recovery_June 2019. 


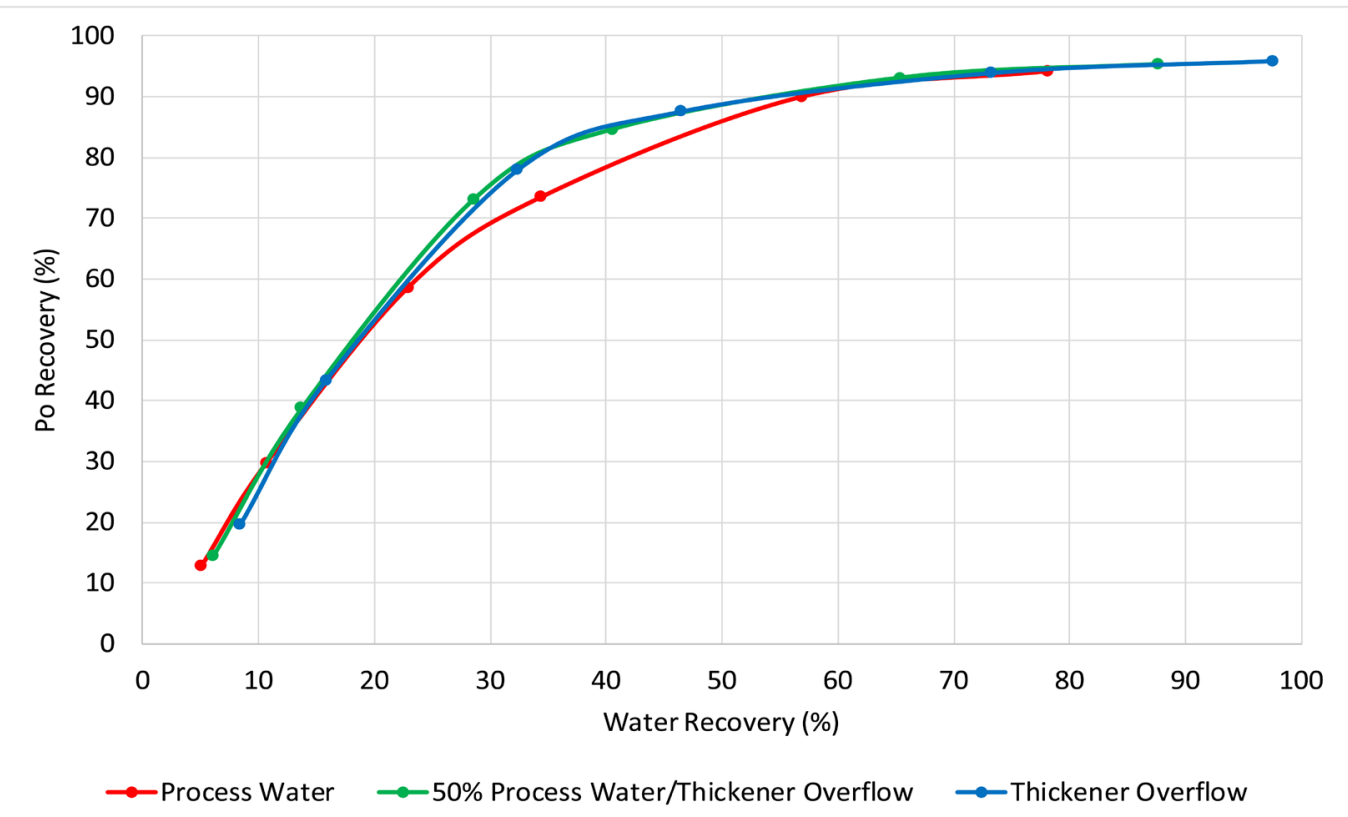

Figure 31. Pyrrhotite recovery versus water recovery-June 2019.

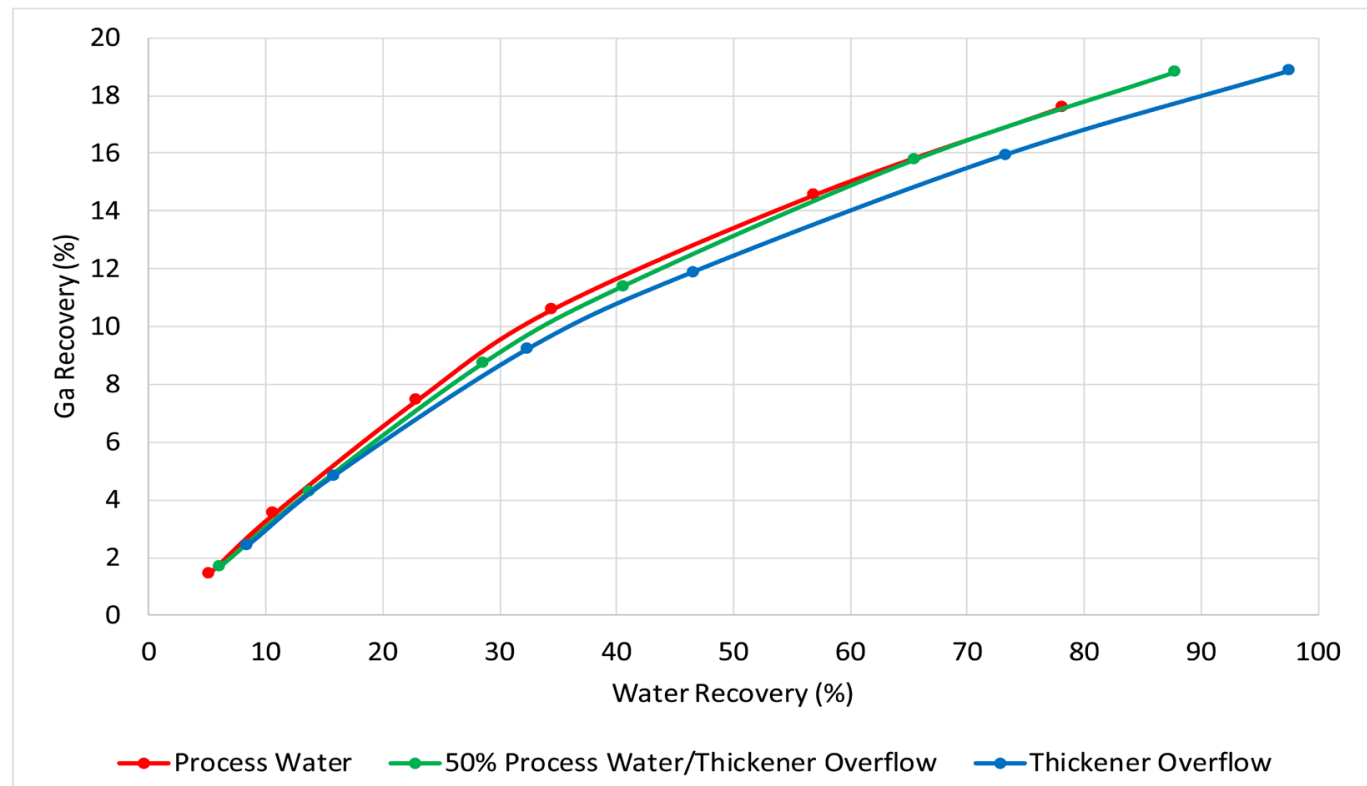

Figure 32. Gangue recovery versus water recovery-June 2019.

Table 10 shows the results of the MANOVA analysis for the days (blocks).

Table 10. Test statistics for the blocks or days-June 2019.

\begin{tabular}{cc}
\hline Statistic & $\mathrm{p}$ value $(\operatorname{Pr}>\mathrm{F})$ \\
Wilks' Lambda & 0.4282 \\
Pillai's Trace & 0.4446 \\
Hotelling-Lawley Trace & 0.3656 \\
Roy's Greatest Root & 0.1111 \\
\hline
\end{tabular}


Since we are using blocks for days and water ratio in the MANOVA analysis, the number of comparisons is $2(\mathrm{~m}=2)$, thus, the significance level $\alpha=0.05 / 2=$ 0.025 (Bonferroni adjustment) was used for the days (blocks) and water ratio analysis. For the day (block) parameter, all the probabilities for the four test statistics were greater than 0.025 , so the null hypothesis for the nickel and copper recoveries between the days (blocks) cannot be rejected or we do not have enough evidence to reject it. This means that the nickel and copper recoveries were not affected by the water chemistry differences, if any, between the days the flotation tests were conducted.

Figure 33 shows the chemistry of the water types for the three days of testing. For all the species, the concentrations for the same water type between the days were approximately the same, which is consistent with the conclusion that the days (blocks) were not significant or did not have any impact on metallurgy.

Table 11 illustrates the results of the MANOVA analysis of the effect of water ratio on nickel and copper recoveries. All the probabilities for the four test statistics were greater than 0.025 with the exception of the Roy's Greatest Root test.

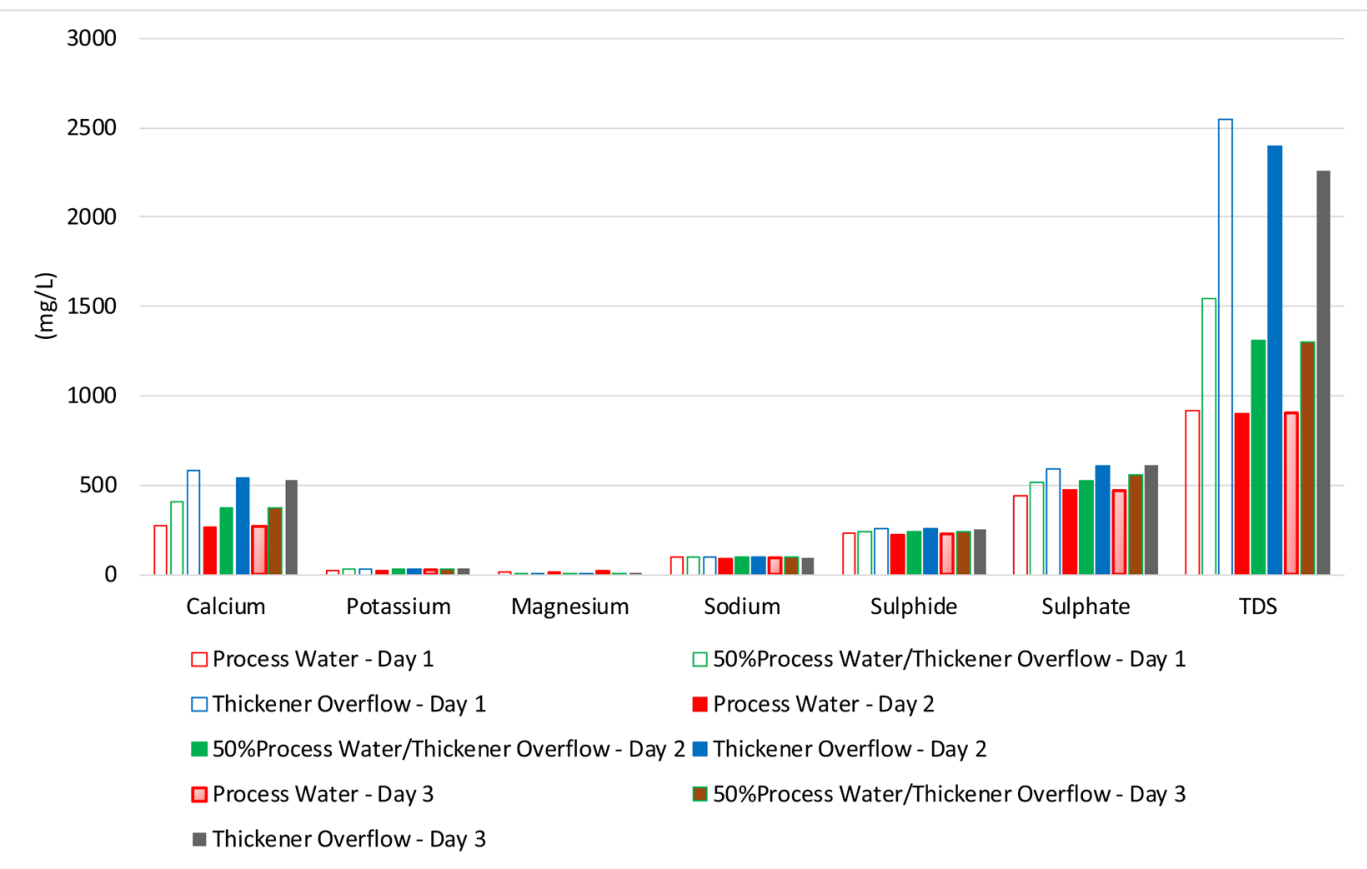

Figure 33. Species concentration in process water, $50 \%$ process water $/ 50 \%$ thickener overflow and thickener overflow-June 2019.

Table 11. Test statistics for the water ratio-June 2019.

\begin{tabular}{cc}
\hline Statistic & $\mathrm{p}$ value $(\operatorname{Pr}>\mathrm{F})$ \\
\hline Wilks' Lambda & 0.0438 \\
Pillai's Trace & 0.0543 \\
Hotelling-Lawley Trace & 0.0591 \\
Roy's Greatest Root & 0.0085
\end{tabular}


Since three out of the four tests were not significant, there was not enough evidence to reject the null hypothesis that the nickel and copper recoveries between the water types were the same. This implies that the water types did not have a significant effect at $95 \%$ level on nickel and/or copper recovery.

\subsubsection{Plant Water-August 2019}

Figure 34 shows the nickel + copper grade versus nickel recovery for the plant water obtained in August 2019. The results were consistent with those obtained in April 2019 and June 2019. When thickener overflow was used, the nickel + copper grade versus nickel recovery decreased. We are $90 \%$ confident that the differences for the nickel + copper grade between process water and those obtained with $50 \%$ process water $/ 50 \%$ thickener overflow and thickener overflow were not due to experimental error or chance (error bars do not overlap).

Figure 35 and Figure 36 illustrate the pyrrhotite recovery versus pentlandite recovery and gangue recovery versus pentlandite recovery for the plant water taken in August 2019. The pyrrhotite recovery increased for the thickener overflow $(50 \%$ and $100 \%)$ relative to that obtained with process water and we are $90 \%$ confident that the increase in recovery was not due to chance (bars do not overlap). This increase in pyrrhotite recovery caused the nickel + copper grade

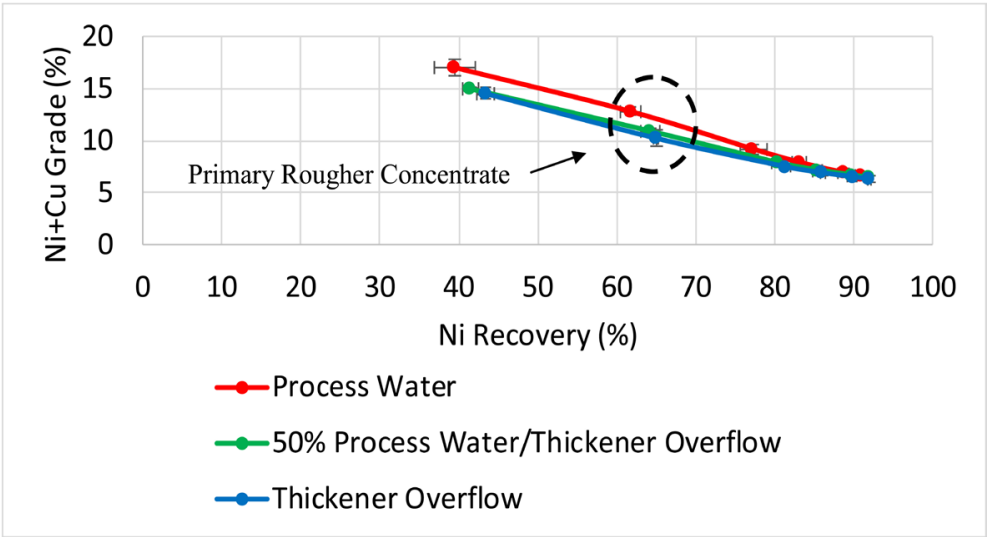

Figure 34. Nickel + copper grade versus nickel recovery-August 2019.

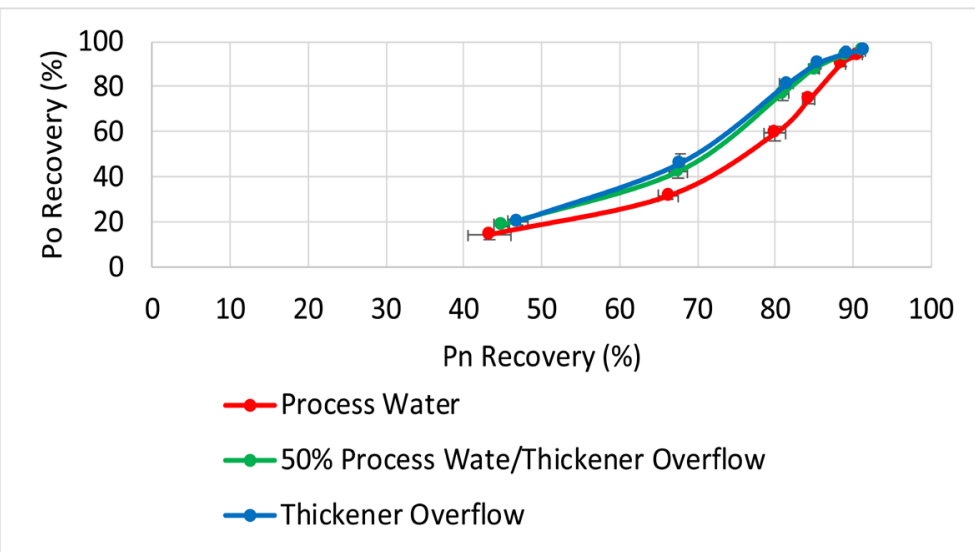

Figure 35. Pyrrhotite recovery versus pentlandite recovery-August 2019. 


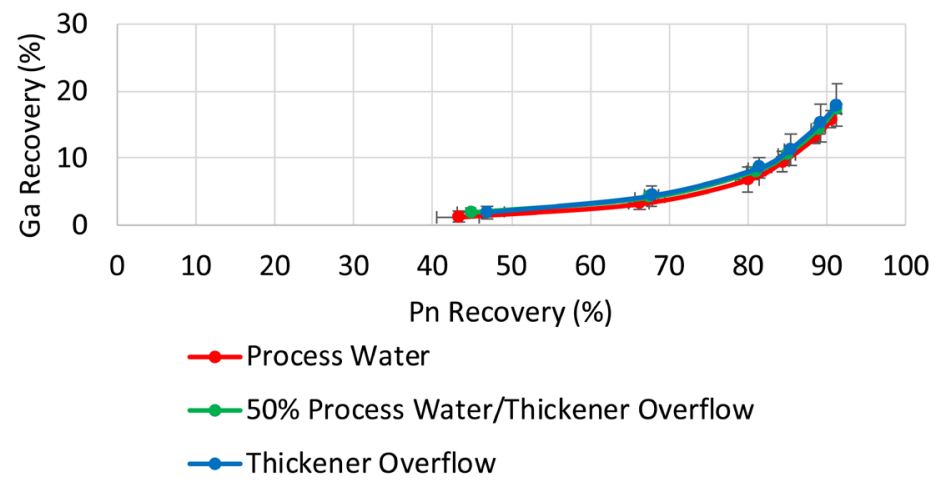

Figure 36. Gangue recovery versus pentlandite recovery-August 2019.

to decrease for the thickener overflow (50\% and 100\%). The gangue recovery curves were similar and the error bars overlapped. Therefore, gangue was not responsible for the lower nickel + copper grade for the thickener overflow.

Figure 37 and Figure 38 illustrate the pyrrhotite recovery versus water recovery and gangue recovery versus water recovery, respectively. The pyrrhotite versus water recovery was not a straight line; thus, the recovery mechanism of pyrrhotite was mainly by true flotation. The gangue recovery as a function of water recovery was almost linear; thus, the recovery was mainly by entrainment for all the water types.

A statistical analysis, MANOVA, was also done for the flotation tests conducted using the plant water obtained in August 2019. Table 12 shows the results of the MANOVA analysis for the days (blocks). The Bonferroni adjustment was 2 (explained previously), thus, the significance level $\alpha=0.05 / 2=0.025$ was

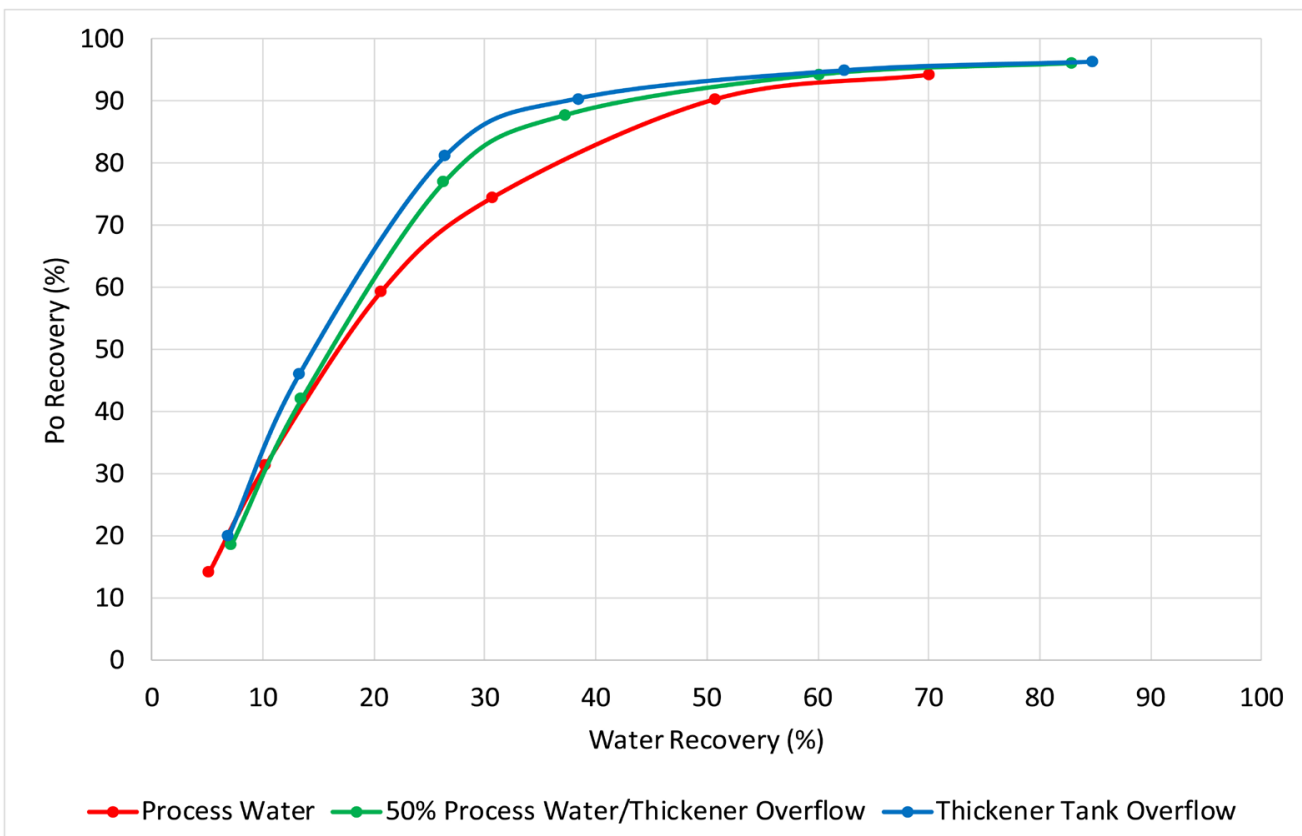

Figure 37. Pyrrhotite recovery versus water recovery-August 2019. 


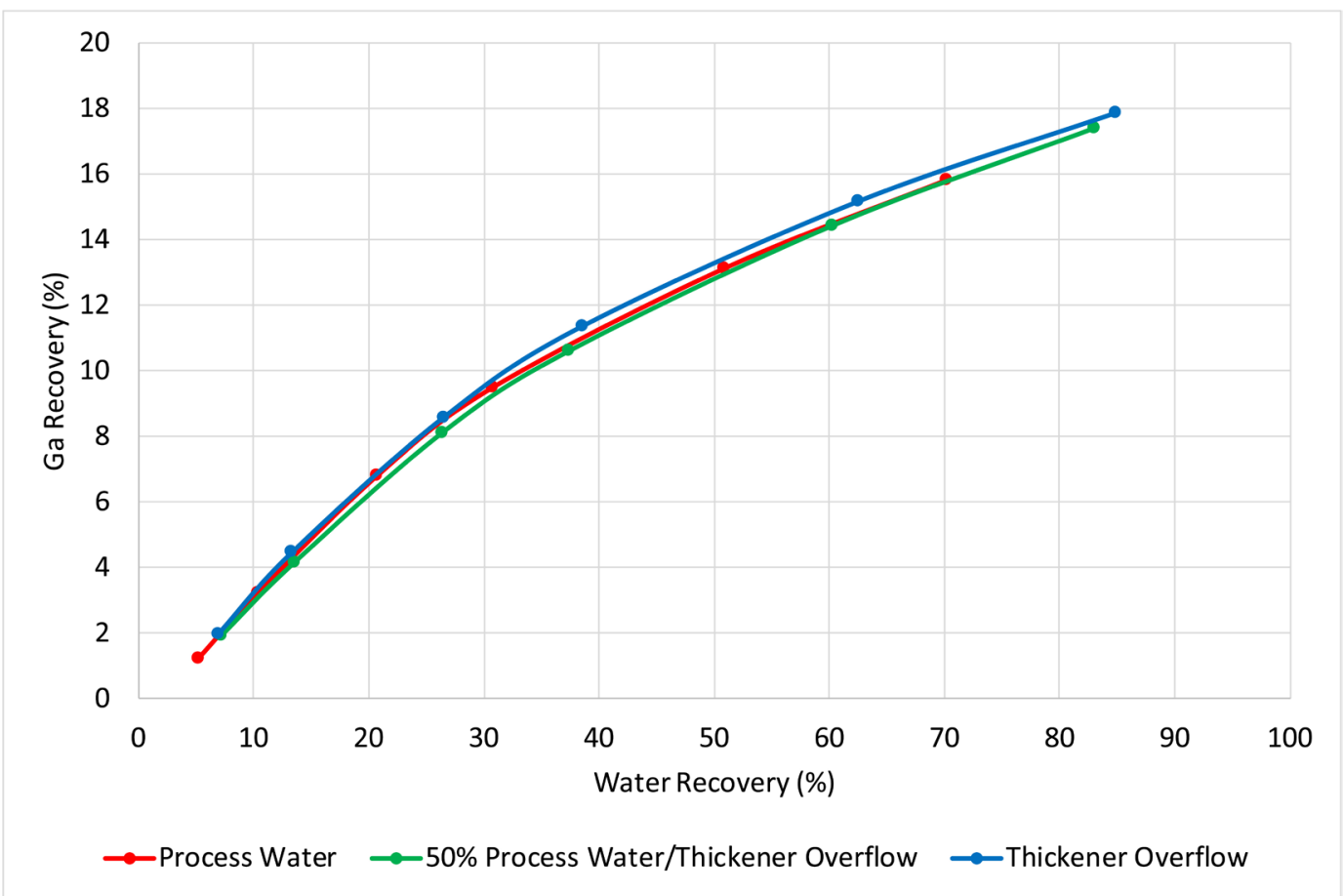

Figure 38. Gangue recovery versus water recovery-August 2019.

Table 12. Test statistics for the blocks or days-August 2019.

\begin{tabular}{cc}
\hline Statistic & $\mathrm{p}$ value $(\mathrm{Pr}>\mathrm{F})$ \\
\hline Wilks' Lambda & 0.4419 \\
Pillai's Trace & 0.3222 \\
Hotelling-Lawley Trace & 0.4597 \\
Roy's Greatest Root & 0.2292 \\
\hline
\end{tabular}

used for the days (blocks) and water ratio analysis. For the day (block) parameter, all the probabilities for the four test statistics were greater than 0.025 implying that the null hypothesis (recoveries were the same) that the nickel and copper recoveries between the days (blocks) cannot be rejected or we do not have enough evidence to reject it. This means that the nickel and copper recoveries were not affected by the water chemistry differences, if any, between the days the flotation tests were done.

Figure 39 illustrates the water chemistry variations for the three days of testing. There were no significant changes in the concentrations of the species except for the TDS of the thickener overflow on Day 3. However, any changes, if any, in the water chemistry between the days of testing did not impact nickel and copper recoveries.

Table 13 illustrates the results of the MANOVA analysis of the effect of water ratio on nickel and copper recoveries. The probabilities for three of the four test statistics were greater than 0.025 and hence insignificant. Thus, there was not enough evidence to reject the null hypothesis that the nickel and copper recoveries 


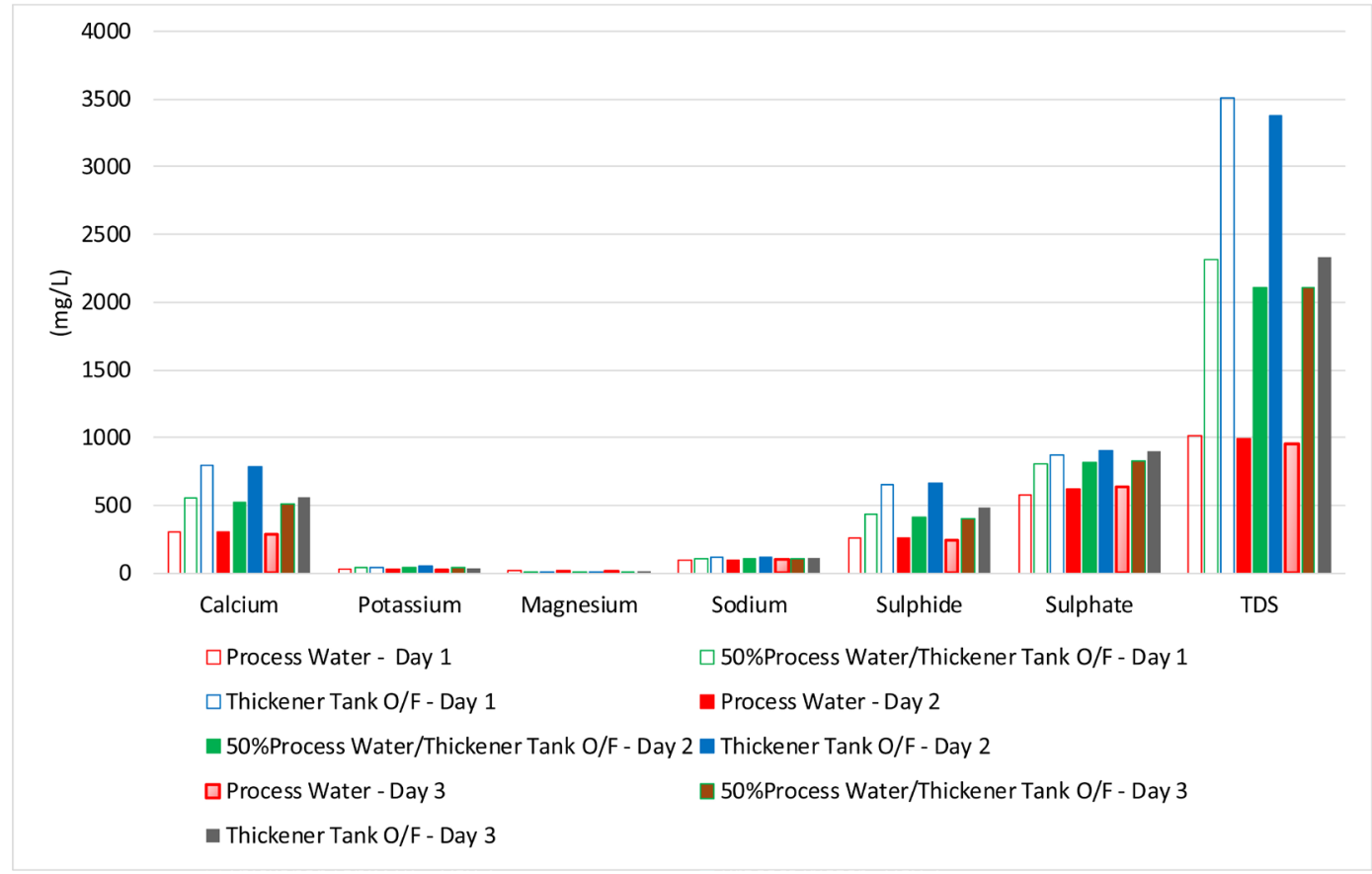

Figure 39. Species concentration in process water, $50 \%$ process water $/ 50 \%$ thickener overflow stream and thickener overflow stream-August 2019.

Table 13. Test statistics for the water ratio-August 2019.

\begin{tabular}{cc}
\hline Statistic & $\mathrm{p}$ value $(\operatorname{Pr}>\mathrm{F})$ \\
\hline Wilks' Lambda & 0.1389 \\
Pillai's Trace & 0.2676 \\
Hotelling-Lawley Trace & 0.1080 \\
Roy's Greatest Root & 0.0180 \\
\hline
\end{tabular}

between the water types were the same. This implies that the water types did not have a significant effect on nickel and copper recoveries.

\section{Discussion}

There are no seasonal variations for the $\mathrm{pH}$, ORP, calcium, sodium, sulfide, sulfate, TDS, thiosalts, total organic carbon, total inorganic carbon and total carbon for the process water, flotation feed side A water, flotation feed side B water and thickener overflow. This implies that it will be easier to implement a water treatment strategy, to treat the thickener overflow, for the mill in question without any significant issues related to seasonal changes that might exist.

Microbial cells can induce significant changes in the surrounding water chemistry, particularly with respect to $\mathrm{pH}$ and ORP [11] [12], and can metabolize certain flotation additives [11] [13] [14] [15], all of which could have serious effects on mineral recovery and flotation selectivity. Laboratory studies have also shown that microbial cells and cellular constituents (e.g., proteins, lipids, DNA) can directly affect mineral flotation due to adsorption onto mineral surfaces [16] 
[17] [18]. Consequently, monitoring of the microbial loading within a flotation system is an important consideration if water is to be recycled, thereby greatly extending its residence time within the milling circuit and possibly allowing microbial numbers to increase to deleterious levels. In this study, the only samples which consistently yielded detectable concentrations of extractable microbial DNA were the process water samples. These were drawn directly from holding ponds that are exposed to the natural environment. Consequently, these samples were more susceptible to seasonal variations in temperature than were the other points sampled within the mill. Warmer summer temperatures may have led to increased microbial growth in the holding ponds, which was reflected by the spike in process water DNA yields during both summer sampling campaigns. It is recommended to sequence the extracted DNA to identify the microbial communities and determine whether they could have negative impacts on water quality and flotation as a result of their metabolic activity. However, the fact that no similar seasonal trends were observed in the chemical parameters our measurements suggest that increased microbial loading and activity in the process water was not having any subsequent detectable effect on water quality.

The fact that no extractable DNA could be detected in the side A and side B flotation feed and thickener overflow samples suggests one of two possibilities. The first is that microbes could have been associated preferentially with the suspended solids (i.e., were attached to the mineral surfaces) which were removed from the water sample prior to DNA extraction. However, we have run separate, solid-phase DNA extractions on selected solids and were unable to detect any DNA in association with the solid phase (data not shown). The second possibility is that the microbial load was simply too low to yield detectable quantities of extractable DNA from the $1 \mathrm{~L}$ samples that were collected. In such cases filtering larger volumes could result in higher yields, but the funding and logistics involved in collecting, freezing, transporting and processing such volumes precluded that possibility at the time. In any case, we believe that the microbial load was so low within the milling circuit that it was unlikely to have any significant effect on flotation. That being said, prolonged recycling of the water within the milling circuit could eventually lead to a buildup of microbial load over time that might adversely affect water quality and flotation. For this reason, continued monitoring of the microbial load and activity throughout the milling circuit is recommended.

Laboratory flotation tests were done using process water and thickener overflow obtained from a concentrator in April 2019, June 2019 and August 2019. The nickel + copper grade in the primary rougher concentrate decreased when 100\% thickener overflow stream obtained in April 2019, June 2019 and August 2019 was used. The implication is that a higher grade of pyrrhotite and possibly gangue (higher gangue recovery was obtained for the 100\% thickener overflow-April 2019 test work only) will report to primary rougher and secondary rougher concentrates. The primary rougher concentrate reports directly to nick- 
el-copper separation; thus, the lower nickel + copper grade in this concentrate may negatively impact the final nickel and copper concentrate specifications. Laboratory tests on an open flowsheet (including copper-nickel separation) using thickener overflow is recommended to assess the impact on final concentrate grades.

When thickener overflow was used, nickel + copper grade versus nickel recovery curves tended to decrease due to higher pyrrhotite (April, June and August 2019) and gangue recoveries (gangue recovery was higher only for April 2019). Figure 40 shows the TIC, TOC and TC concentrations for the water samples taken prior to the flotation tests April 2019, June 2019, and August 2019. Figure 41 illustrates the TDS for the water samples taken prior to the flotation tests in April 2019, June 2019 and August 2019. The thickener overflow tended to have higher quantities of TOC and TC than the process water; these species (TOC and TC) may originate from residual xanthate and its decomposition products, frothers and flocculants. These higher concentrations of TOC and TC in

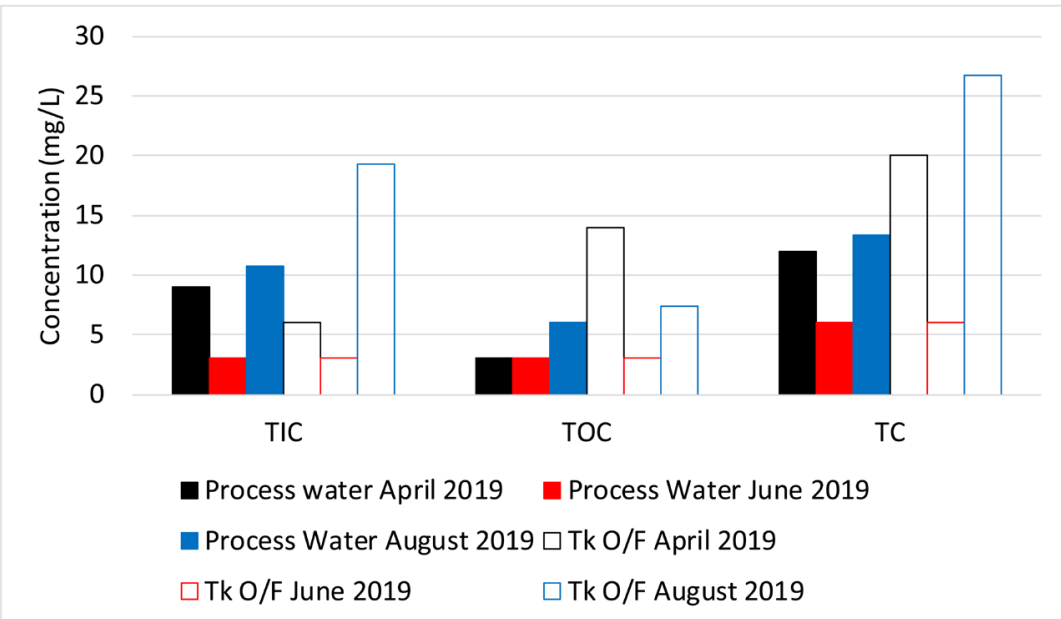

Figure 40. TIC, TOC, TC for process water and thickener overflow for April, June and August 2019-water samples taken prior to flotation test.

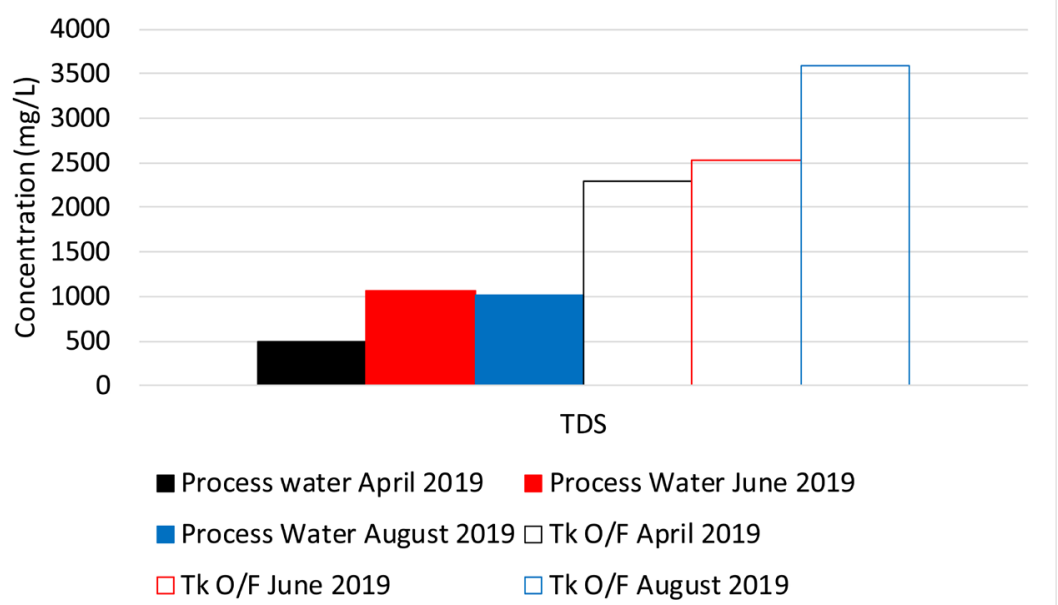

Figure 41. TDS for process water and thickener overflow for April, June and August 2019-water samples taken prior to flotation test. 
the thickener overflow could have caused higher pyrrhotite recovery through accidental activation. For example, the accumulation of the decomposition products of xanthate due to water reuse caused non-selective adsorption in copper-lead-zinc flotation [19]. Therefore, in the results presented in this publication, higher pyrrhotite recovery obtained with thickener overflow could have been caused by the higher TOC and TC concentrations.

For the flotation tests performed with thickener tank overflow stream in April 2019, the higher gangue recovery may have resulted by the higher concentrations of TOC and TC as well as higher recovery by entrainment as discussed earlier. From Figure 41, it can be observed that the TDS of thickener overflow was much higher than that observed for the process water. The TDS in water generally causes the air bubbles to be smaller, higher bubble surface area flux, causing a higher particle-bubble collision probability [1]. The higher bubble surface area flux caused by the thickener overflow may provide more bubble surface area for the pyrrhotite to float. Also, when the TDS is higher in the water, some species can cause accidental of unwanted minerals [1]. This may be another cause for higher pyrrhotite recovery when the thickener overflow is used. A surface analysis study is beyond the scope of this publication. However, a surface analysis investigation will be performed in the future to establish the species, if any, responsible for pyrrhotite and gangue flotation.

Figure 42 and Figure 43 show the box plot for the nickel and copper recoveries obtained for the water types used for the flotation tests performed with water obtained in April 2019, June 2019 and August 2019. The nickel and copper recoveries obtained with the thickener overflow were generally higher than those obtained with process water for their respective months or sampling periods.

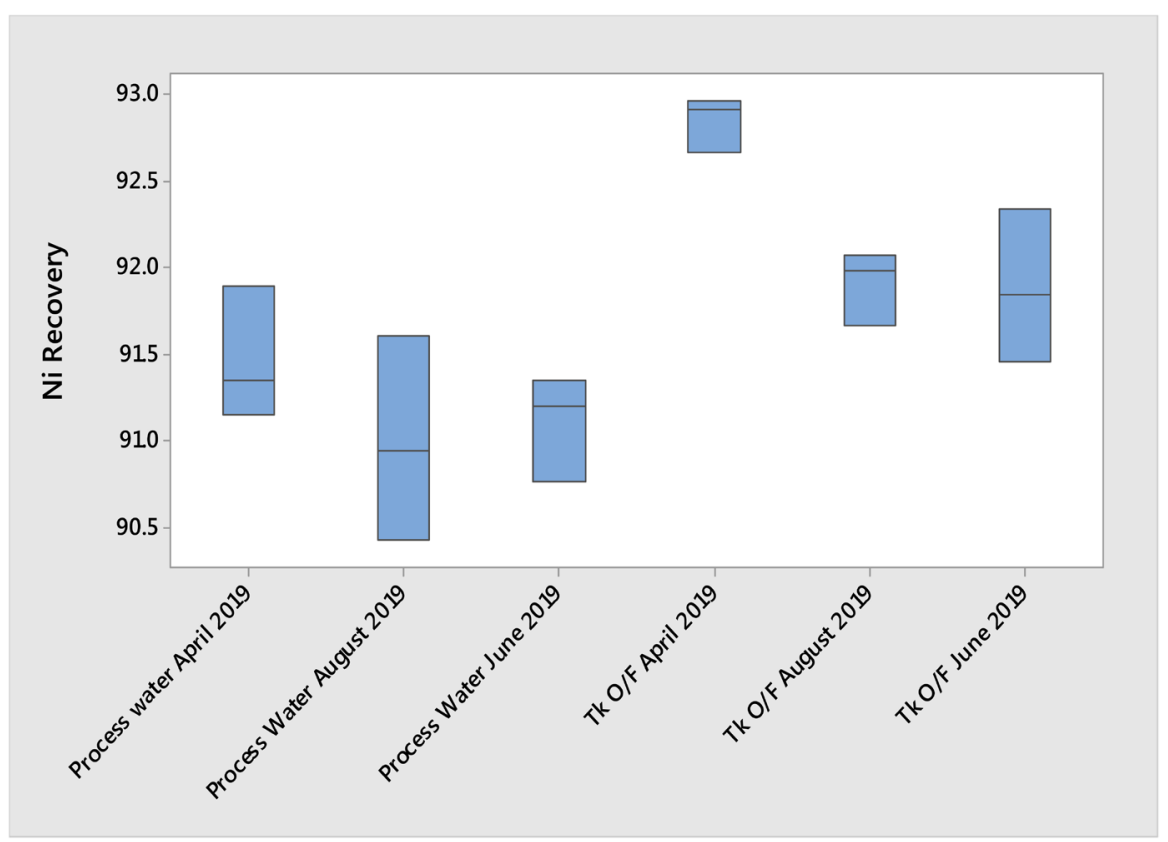

Figure 42. Nickel recovery for process and thickener overflow for April, June and August 2019 used in laboratory flotation tests. 


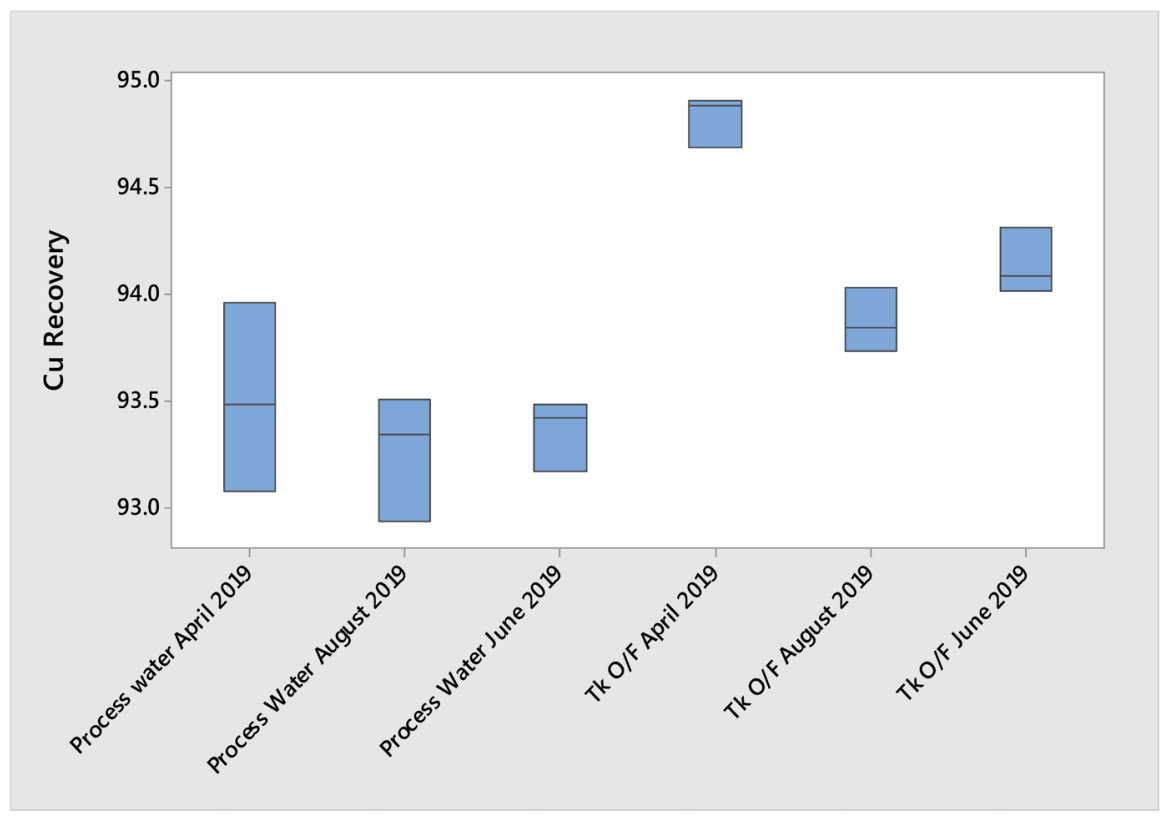

Figure 43. Copper recovery for process water and thickener overflow for April, June and August 2019 used in laboratory flotation tests.

The MANOVA analysis for the April 2019 test work showed that the nickel and copper recoveries were significantly (95\% confidence) higher for thickener overflow compared to those for process water. However, for the nickel and copper recoveries obtained with thickener overflow for the months of June 2019 and August 2019 were not significantly higher compared to those for process water. When the null hypothesis cannot be rejected, it implies that we do not have enough evidence to reject it (nickel and copper recoveries between the water types are the same). This means that more tests are required and that the recoveries between water types may actually be different. However, it is important to point out that when the thickener overflow was used, there was no loss in nickel and copper recoveries.

It is recommended to investigate the impact of complete thickener overflow recirculation as a follow-up of this study. Also, various water treatment technologies on thickener overflow should be tested. The water treatment technology that will be chosen, and its effect on the percentage of the thickener overflow that has to be treated, will play an important role in the economics.

\section{Conclusions}

There were no seasonal or other trends (between the seasons) during the sampling period for the chemistry (species in solution such as calcium, thiosulphate etc.) of the process water, side A flotation feed water, side B flotation feed water and thickener overflow streams. Although process water samples displayed clear seasonal trends with respect to microbial loading, the increased summer loads did not appear to have adversely affected the water quality and flotation parameters measured. 
The nickel + copper grade versus nickel recovery decreased when higher amounts of the thickener overflow stream (50\% and 100\%) were used. The lower nickel + copper grade versus nickel recovery in the presence of the thickener overflow stream were due to higher pyrrhotite and gangue recoveries (non-sulphide gangue recovery was higher for April 2019 only).

For nickel recovery, the tests conducted using thickener overflow stream (100\% thickener overflow) obtained in the April 2019 showed an improvement relative to that obtained with process water. For copper recovery, the tests conducted with $50 \%$ and $100 \%$ thickener overflow (April 2019) resulted in an improvement relative to those obtained with process water.

Most likely the higher pyrrhotite recovery in the presence of the thickener overflow stream was due to the higher TDS, TOC and TC. The higher TDS in the water will most likely create smaller bubbles and higher bubble surface area flux, which can increase particle-bubble collision efficiency resulting in higher recovery. Whereas, the TOC and TC may cause inadvertent activation of pyrrhotite and gangue.

\section{Acknowledgements}

The authors would like to thank the Sylvain Dillon and Joshua Thomas for their hard and excellent work in the laboratory.

\section{Conflicts of Interest}

The authors declare no conflicts of interest regarding the publication of this paper.

\section{References}

[1] Liu, W., Moran, C.J. and Vink, S. (2013) A Review of the Effect of Water Quality on Flotation. Minerals Engineering, 53, 91-100. https://doi.org/10.1016/j.mineng.2013.07.011

[2] Levay, G. and Schumann, R. (2006) A Systematic Approach to Water Quality Management in the Minerals Processing Industry. Water in Mining Conference, Brisbane, 14-16 November 2006.

[3] Peters, N.E. and Meybeck, M. (2000) Water Quality Degradation Effects on Freshwater Availability: Impacts of Human Activities. Water International, 25, 185-193. https://doi.org/10.1080/02508060008686817

[4] Muzenda, E. (2010) An Investigation into the Effect of Water Quality on Flotation Performance. International Journal of Chemical, Molecular, Nuclear, Materials and Metallurgical Engineering, 4, 562-566.

[5] Levay, G., Smart, R.ST.C. and Skinner, V.M. (2001) The Impact of Water Quality on Flotation Performance. The Journal of the South African Institute of Mining and Metallurgy, 101, 69-75.

[6] Slatter, K.A., Plint, N.D., Cole, M., Dilsook, V., De Vaux, D., Palm, N. and Oostendorp, B. (2009) Water Management in Anglo Platinum Process Operations: Effects of Water Quality on Process Operations. Abstracts of the International Mine Water Conference, Pretoria, South Africa, 19-23 October 2009, 46-55. 
[7] Zhang, J. and Zhang, W. (2012) Multi-Scale Investigation of Applying Secondary Effluent in Sulfide Flotation. Water in Mineral Processing-Proceedings of the 1 st International Symposium, Seattle, WA, USA, 279-290.

https://www.amazon.com/Water-Mineral-Processing-Proceedings-International/dp 10873353498\#reader_0873353498

[8] Johnson, R.A. and Wichern, D.W. (2019) Applied Multivariate Statistical Analysis. Pearson and Practice Hall. 6th Edition, Upper Saddle River, New Jersey, USA.

[9] Napier-Munn, T.J. (2012) Statistical Methods to Compare Batch Flotation GradeRecovery Curves and Rate Constants. Minerals Engineering, 34, 70-77. https://doi.org/10.1016/j.mineng.2012.03.036

[10] Liu, L., Rao, S.R. and Finch, J.A. (1993) Technical Note, Laboratory Study of Effect of Recycle Water on Flotation of a Cu/Zn Sulphide Ore. Minerals Engineering, 6, 11, 1183-1190. https://doi.org/10.1016/0892-6875(93)90095-5

[11] Chockalingam, E., Subramanian, S. and Natarajan, K.A. (2003) Studies on Biodegradation of Organic Flotation Collectors Using Bacillus polymyxa. Hydrometallurgy, 71, 249-256. https://doi.org/10.1016/S0304-386X(03)00163-4

[12] Liu, W., Moran, C.J. and Vink, S. (2013) Mechanism Study of the Impact of Water-Borne Bacteria on Flotation. International Journal of Mineral Processing, 123, 39-45. https://doi.org/10.1016/j.minpro.2013.04.015

[13] Deo, N. and Natarajan, K.A. (1998) Biological Removal of Some Flotation Collector Reagents from Aqueous Solutions and Mineral Surfaces. Minerals Engineering, 11, 717-738. https://doi.org/10.1016/S0892-6875(98)00058-2

[14] Chen, S.H., Gong, W.Q., Mei, G.J., Zhou, Q., Bai, C.P. and Xu, N. (2011) Primary Biodegradation of Sulfide Mineral Flotation Collectors. Minerals Engineering, 24, 953-955. https://doi.org/10.1016/j.mineng.2011.01.003

[15] Araujo, D.M., Yoshida, M.I., Takahashi, J.A., Carvalho, C.F. and Stapelfeldt, F. (2010) Biodegradation Studies on Fatty Amines Used for Reverse Flotation of Iron ore. International Biodeterioration \& Biodegradation, 64, 151-155. https://doi.org/10.1016/j.ibiod.2010.01.004

[16] Liu, W., Moran, C.J. and Vink, S. (2013) Impact of Chalcopyrite Depression by Water-Borne Bacteria in Pure and Combined Mineral Systems. International Journal of Mineral Processing, 123, 18-24. https://doi.org/10.1016/j.minpro.2013.04.017

[17] Liu, W., Moran, C.J. and Vink, S. (2016) The Adverse Effect of Disrupted Water-Borne Bacteria Cells on Flotation. International Journal of Mineral Processing, 157, 128-133. https://doi.org/10.1016/j.minpro.2016.10.007

[18] Vasanthakumar, B., Ravishankar, H. and Subramanian, S. (2012) A Novel Property of DNA-As a Bioflotation Reagent in Mineral Processing. PLoS ONE, 7, e39316. https://doi.org/10.1371/journal.pone.0039316

[19] Ozkan, S.G. and Acar, A. (2004) Investigation of Impact of Water Type on Borate Ore Flotation. Water Research, 38, 1773-1778.

https://doi.org/10.1016/j.watres.2003.12.036 